\title{
A review on cutting tool technology in machining of Ni-based superalloys
}

\author{
Wei Fan ${ }^{1}\left(\mathbb{D} \cdot\right.$ Wei $^{\mathrm{Ji}^{2,3}} \cdot$ Lihui Wang $^{3} \cdot$ Lianyu Zheng $^{1} \cdot$ Yahui Wang ${ }^{1}$ \\ Received: 13 April 2020 / Accepted: 10 August 2020 / Published online: 17 September 2020 \\ (C) The Author(s) 2020
}

\begin{abstract}
In this paper, a state-of-the-art review on cutting tool technology in machining of Ni-based superalloys is presented to better understand the current status and to identify future directions of research and development of cutting tool technologies. First, past review articles related to the machining of Ni-based superalloys are summarized. Then machinability of superalloys is introduced, together with the reported methods used in cutting tool design. The current researches on cutting tools in the machining of superalloys are presented in different categories in terms of tool materials, i.e., carbide, ceramics, and Polycrystalline cubic boron nitride (PCBN). Moreover, a set of research issues are identified and highlighted to improve the machining of superalloys. Finally, discussions on the future development are presented, in the areas of new materials/geometries, functional surfaces on the cutting tool, and data-driven comprehensive optimization.
\end{abstract}

Keywords Ni-based superalloys $\cdot$ Machining $\cdot$ Cutting tool $\cdot$ Tool material $\cdot$ Tool geometry

\begin{tabular}{ll}
\multicolumn{2}{l}{ Abbreviations } \\
AFM & Atomic force microscopy \\
BUE & Build-up edge \\
BUL & Built-up layer \\
CBN & Cubic boron nitride \\
CNC & Computerized numerical control \\
CVD & Chemical vapor deposition \\
EDX & Energy-dispersive X-ray \\
FEM & Finite element method \\
GA & Genetic algorithm \\
HPC & High-pressure coolant \\
HSM & High-speed machining \\
MAB & Micro-abrasive blasting \\
MQL & Minimum quantity lubrication
\end{tabular}

Lihui Wang

lihuiw@kth.se

1 School of Mechanical Engineering and Automation, Beihang University, Beijing 100191, China

2 Sandvik Coromant, 12679 Stockholm, Sweden

3 Department of Production Engineering, KTH Royal Institute of Technology, Stockholm 10044, Sweden
PCBN Polycrystalline cubic boron nitride

PVD Physical vapor deposition

\section{Introduction}

A cutting tool, considered as the "teeth" of a machine tool, is one of the principal manufacturing resources in the machining field because it is in touch with machined workpiece directly and sometimes directly determines the machining quality and efficiency of the workpiece. However, they have been considered as standard products in practice, so that tool selection is centered in computer-aided process planning [1]. Nevertheless, the research on cutting tools has not been active other than proper selection. It is therefore still challenging to guarantee a long tool life with high quality in machining of difficult-to-cut materials, e.g., superalloys.

A superalloy is a high-performance alloy which exhibits several key characteristics: excellent mechanical strength, resistance to thermal creep deformation, good surface stability, and resistance to corrosion or oxidation. Here, Ni-based superalloy is one of the most typical classes of the superalloy, and it is mainly applied in aerospace, oil and gas mining, petrochemical, and other industries. Its market share accounts for more than half of the entire superalloy market. Generally, it contains $10-20 \% \mathrm{Cr}$, up to $8 \% \mathrm{Al}$ and $\mathrm{Ti}, 5-10 \% \mathrm{Co}$, and 
small amounts of $\mathrm{B}, \mathrm{Zr}$, and $\mathrm{C}$. Other common additions are $\mathrm{Mo}, \mathrm{W}, \mathrm{Ta}, \mathrm{Hf}$, and $\mathrm{Nb}$. Its major phase refers to gamma $(\gamma)$, gamma prime $\left(\gamma^{\prime}\right)$, carbides, ${ }^{1}$ and so on. It has been used in load-bearing structures to the highest homologous temperature of any common alloy system, e.g., gas turbines (turbine blades), solar thermal power plants (stainless steel rods containing heated water), steam turbines (turbine blades and boiler housing), and heat exchangers for nuclear reactor systems. Figure 1 shows the application of Ni-based superalloys used in a Rolls-Royce XWB turbofan engine [2]. However, accompanied by the delivered high performances, there are many difficulties in processing of Ni-based superalloys, especially in machining, e.g., short tool life and low machining efficiency, owing to high cutting force, high cutting temperature, machining hardening, and difficulty of chip breaking [3].

Cutting tool technologies have been developed for more than 100 years in metal cutting. Cemented carbide was first reported in 1927, of which the coating technologies, physical vapor deposition (PVD) and chemical vapor deposition (CVD), were invented in the 1960s [4]. A ceramic, $\mathrm{Al}_{2} \mathrm{O}_{3}$, was used as cutting tool in 1905 [5], and PCBN was invented in the 1950s [6]. There have been numerous research publications as well as technical surveys on cutting tool technologies in the machining of superalloys. It is also evident that the trend of cutting tool technology has undergone drastic changes. To the best of the authors' knowledge,

there have been several articles referring to a certain perspective of cutting tool technology, and there has been no comprehensive review of cutting tools in the machining of Ni-based superalloys. Therefore, this paper aims to provide a review on cutting tools developed for the machining of Ni-based superalloys. The remainder of this paper is organized as follows: Section 2 provides an excerpt of the past review publications on the machining of superalloys. Cutting tool design methods are highly connected to tool performance. Thus, Section 3 introduces the machinability of superalloys and current methods used in metal cutting in brief. Section 4 describes various research and developments, including the machinability of superalloys and cutting tool technologies. Recap on tool technologies in machining of superalloys is presented in Section 5. Finally, Section 6 gives a set of future trends in this field.

\section{Reported review articles}

Several review articles on superalloy machining have been published, including material machinability, surface integrity, tool wear, and machining condition.

Material machinability is one of the most important topics in the field of machining, especially for difficult-to-cut

\footnotetext{
${ }^{1}$ Carbon, added at levels of $0.05-0.2 \%$, combined with reactive and refractory elements such as titanium, tantalum, and hafnium to form carbides.
}

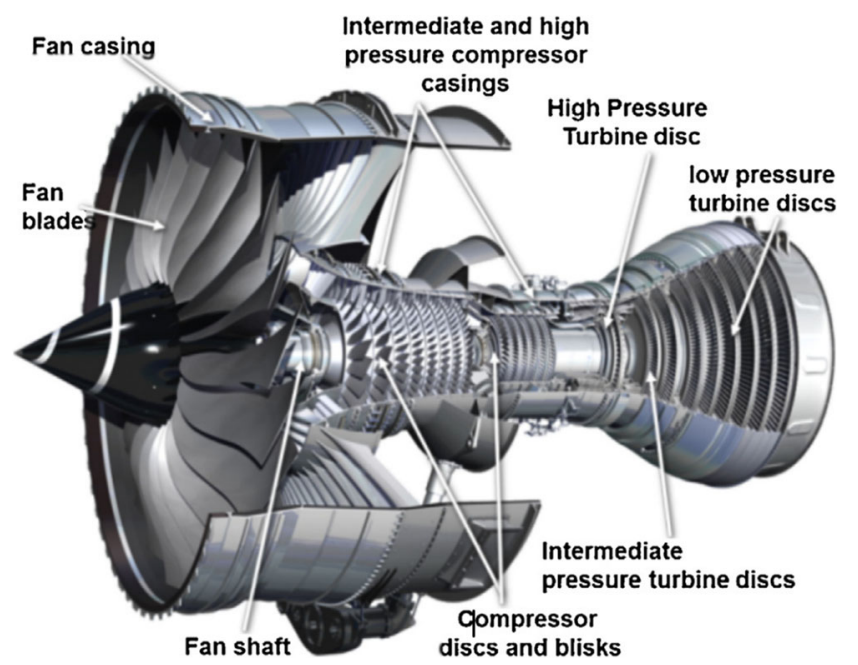

Fig. 1 Rolls-Royce XWB turbofan engine [2]

materials. In general, there are too many factors related to machinability, yet no widely accepted ways to quantify machinability; therefore, it has been performed case by case. Ezugwu et al. [7] was focused on the machinability of a set of Ni-based superalloys in terms of wrought/cast superalloys, alloying elements/microstructure, and strengthening/heat treatment. These factors were associated with cutting performances, e.g., tool wear, surface integrity, and tool failure. They pointed out that the machined surface abuse and tool life were the most important factors. Moreover, they presented an up-to-date review with updating the results of the research on tool materials and coolants [8]. Cubic boron nitride (CBN) and PCBN tool materials could be capable to produce high quality at a high cutting speed and the conventional coolant might not reach the cutting zone. Arunachalam and Mannan [9] also reviewed the machinability of superalloys in highspeed machining (HSM) of Inconel 718, a Ni-based superalloy. They discussed cutting tool materials, coolants, and surface integrity in HSM. Their conclusions showed that the chemical composition should be taken into account of the machinability of Ni-based superalloys.

With further development, the material machinability has been almost impossible to cover all of its perspectives within one review paper. Therefore, surface integrity, the most important consideration in machining of superalloys, has attracted a large amount of research interests, and it refers to surface defects, surface roughness, white layer, dark layer, work hardening layer, macrostructure deformation, and residual stresses. Guo et al. [10] focused on surface integrity characterization, especially residual stresses. Multi-scale simulation technology was highlighted in their work: (1) micro-scale simulation in terms of micro-scale in-process parameters, micro-scale residual stress, size effect, microstructure effect, and microtribology; and (2) nano-scale simulation in terms of chemical transport/diffusion. Ulutan and Ozel [11] analyzed surface integrity in the machining of Ni-based superalloys, and 
highlighted several surface integrity indexes, including surface defects, macrostructure alterations, work hardening layer formation and microhardness, surface roughness, and residual stresses. In their work, the methods of analysis and investigation were introduced, as well as a brief introduction to a tool material in which uncoated/coated carbides and CBN were discussed in machining of Ni-based superalloys. Thakur and Gangopadhyay [12] discussed how surface integrity was influenced by cutting conditions including cutting parameters, cutting environment, tool condition (mainly cutting edge preparation), tool materials, and tool wear. The relationships between applied conditions and surface qualities have been explained.

Tool wear in machining of superalloys is also a critical issue since it is closely related to the machining quality. Zhu et al. [13] characterized tool wear and stated the tool failure mechanisms. They stressed the importance of monitoring, prediction, and control of tool wear and non-equilibrium thermodynamics and thermal-mechanical coupling. Similarly, Akhtar et al. [14] reviewed tool wear in machining of $\mathrm{Ni}$ based superalloys from a wear mechanism point of view. They found that the cutting speed was a quite sensitive factor influencing tool wear mechanics. Tool wear can affect surface integrity, which has been investigated by Liang et al. [15]. They pointed out that the experimental data were the major resources, rather than theoretical models, and that the research is also fairly limited.

In response to the high cutting temperature in machining of superalloys, advanced cooling methods have attracted great attention. Considering environmental conscious, cutting fluids used in machining of difficult-to-cut materials were discussed by Shokrani et al. [16], in which dry machining, minimum quantity lubrication (MQL), and chilled air and cryogenic machining were highlighted from the environmental perspective. Mohsan et al. [17] reviewed the progress toward improvement in surface integrity of Inconel 718 under high-pressure coolant (HPC). In general, HPC could improve surface roughness with lower tensile residual stresses at a relatively high cutting speed.
Advanced cutting technologies for Ni-based superalloys have been reviewed including cooling strategies (HPC and cryogenic machining) and hybrid cutting processes (vibration-assisted machining, laser-assisted machining) [2]. Cutting tool was mentioned in the reviews in terms of some specific perspectives, e.g., angles and materials. However, a cutting tool, as a whole, cannot be divided into several independent components which are optimized individually to improve cutting performance. Therefore, the research on cutting tool technologies should be highlighted to deliver highperformance cutting tools in the machining of superalloys. In this paper, all the related aspects of cutting tool technologies are shown in Fig. 2, where machinability of superalloys and cutting tool design methods are the basis, on top of which the cutting tool is reviewed according to its material categories and with respect to the research on tool failure, material, geometry, condition, and cutting chip.

\section{Machinability of superalloys and cutting tool design}

The machinability of a difficult-to-cut material and design method of a cutting tool are two important aspects of cutting tool technologies.

\subsection{Machinability of superalloys}

With high cutting force, low thermal conductivity, abrasiveness, and work hardening, the low machinability of Ni-based superalloys generates high heat on cutting edge in the process of machining, resulting in short tool life [18]. From a material point of view, the machinability of Ni-based superalloys is related to its content of chemical element and heat treatment. Here, Ni, the major element of Ni-based superalloys, affects the machinability significantly, as shown in Fig. 3, where the cutting temperature is raised with the content of $\mathrm{Ni}$ increasing,
Fig. 2 Reviewed aspects of cutting tool technologies
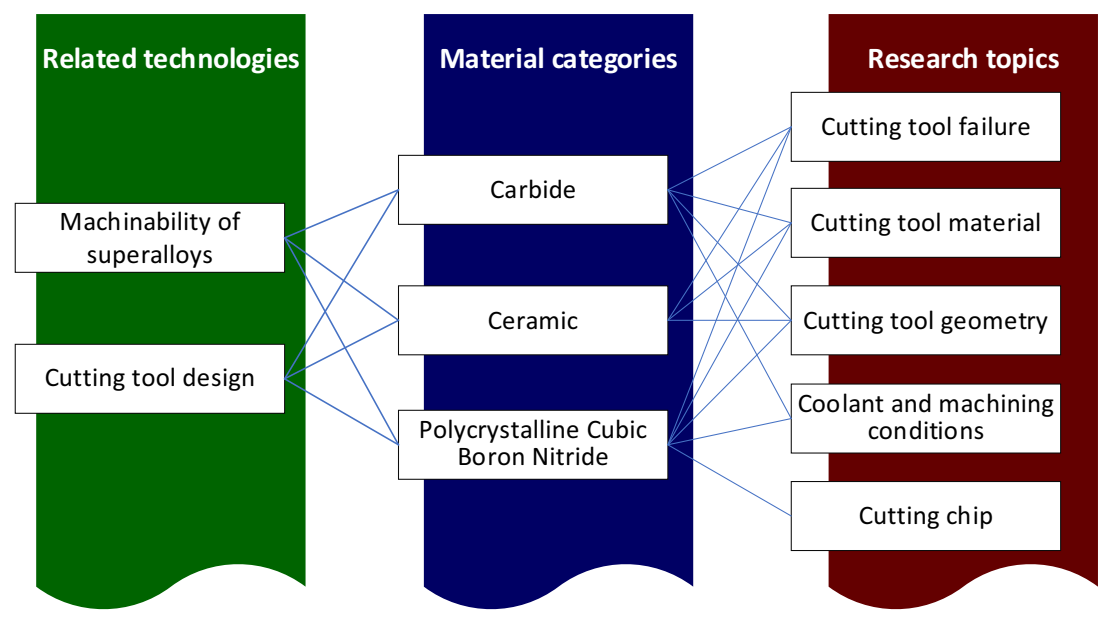


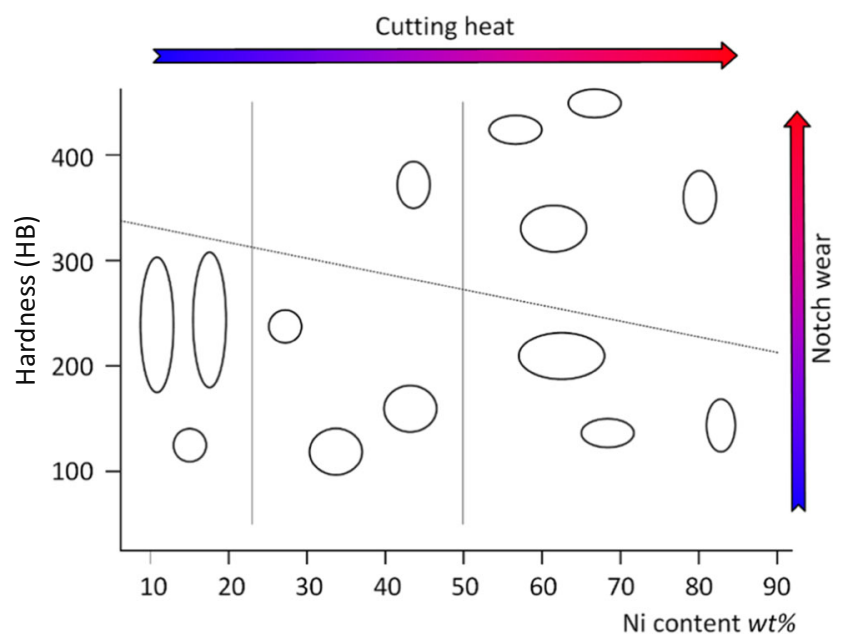

Fig. 3 Machinability of superalloys [19]

and the tool notch wear is increased along with the hardness increasing. The chemical composition of superalloys should be associated with the hardness when determining machining conditions [9].

The grain size of superalloys is another important factor to its machinability. Tool life and surface abuse were suggested as the two most important indicators for the machinability of Ni-based superalloys [20]. The grain size of wrought Inconel 718 had a minor or no influence on the flank wear; however, the notch wear was strongly connected with large grains [21]. Interestingly, the ratio of feed rate to the average grain size strongly affected the initial tool wear and cutting force behavior [22]. In addition, the chip compression ratio has been mentioned as one of the critical indicators of machinability, especially for cutting condition determination in high-speed machining [23].

\subsection{Cutting tool design}

For any cutting tool technologies, cutting tool determination in terms of geometries and materials is an important process to make them happen, which generally refers to cutting tool design and its methods. Several methods are summarized as follows:

- Theory-based approach: mathematical models to explain the phenomenon of cutting processes based on the physical models, i.e., cutting force, heat, and material deformation [24, 25], have been used to design tool. Fundamentally, a set of assumptions, enabling the developed physics models to be applied to cutting, low accuracy of those models.

- Experimental method: targeting a specific machining requirement, the best performance tool is selected among a set of candidates with designed tool angles and materials by observing the results in machining tests [26-28].
Obviously, the potential range of tool parameters should present in the candidates of the test, which limits the covered tool parameters. Also, the designed tools are sensitive to the experimental setups used in testing, e.g., machine tools and fixtures.

- Finite element method (FEM): it has been employed in simulation of the cutting process, targeting reducing the number of physical experiments [29-31], and a well-developed FEM model can therefore provide a reference for cutting tool design [32]. Although FEM has a great potential benefit in terms of cost and efficiency, the cutting process cannot be represented accurately, in which it is hard to guarantee a critical design requirement of cutting tools, especially in machining of superalloys.

- Expert systems, emulating the human experts, were employed in cutting tool design [33, 34], by reasoning based on cutting tool knowledge and cutting data. Because of the limitation of using if-then rules in the system, it is still difficult to represent the cutting process precisely.

- Computational method: many algorithms, e.g., Genetic Algorithm (GA), Tabu search, and simulated annealing, were used in cutting tool design and machining parameter optimization $[35,36]$. The methods highlight the optimization process, and activate multi-objective optimization in tool design, based on cutting test data and developed models.

- Machining process-enabled tool design: considering the complexity of the cutting process, the cutting tool has been proposed to be designed together with machine condition optimization and cutting performance design [37]. A further development regarding system and implementation was carried out by using IDEF0 [38, 39], which was numerically validated $[40,41]$.

\section{Current status of cutting tool technology in machining of superalloys}

This section reviews the cutting tool technology by following tool materials, i.e., carbide tool, ceramic tool, and PCBN tool. From a cutting tool design perspective, the experiment-based approach still dominates others given its reliability. Therefore, the major results in this section were drawn based on experiments.

\subsection{Carbide}

Carbides are the most commonly used tool materials in machining of Ni-based superalloys currently, owing to their 
excellent balance between cost and performance, especially coated carbides.

\subsubsection{Tool failure}

The tool failure of a carbide tool is closely related to tool materials and cutting conditions generally. For an uncoated carbide tool, chipping and/or fracture are the dominant failures in turning of Ni-based superalloys, which was experimentally discovered by Ezugwu and Pashby [42], and Thakur and Gangopadhyay [43]. A built-up edge (BUE) and a built-up layer (BUL) were found on the inserts in dry turning of Inconel 718 [44]. Whereas the tool failure patterns of a PVD-coated carbide tool (a TiN and a TiNRiCNRiN), flank wear, excessive chipping, and flaking of tool materials closed to the cutting edge or on the rake face were reported as the dominant wear patterns, flank wear and notching were dominant failures of a CVDcoated carbide tool $\left(\mathrm{TiC} / \mathrm{Al}_{2} \mathrm{O}_{3} / \mathrm{TiN}\right)$ [20]. Moreover, chipping of cutting edge and notching could be more significantly resisted with a PVD-coated tool [43].

In interrupted machining, crack formation and plastic deformation at the coating were found on a PVD TiN-coated tool [45]. In addition, in a milling operation, a BUE was found at both tools by using a TiAlN tool and a CrN-coated carbide tool [46]. In terms of how a milling tool enters a cut, tool flank wear propagation in up-milling operations was more rapid than that in down-milling operations [47]. Many other tool failure patterns, e.g., flank wear, notch wear, chipping, and BUE, were found in milling [48], as shown in Fig. 4.
Abrasive and adhesive are the most dominant wear mechanisms in oblique finish turning of Inconel 718 by an uncoated carbide, a TiAlN-coated tool, and a TiCN/Al $\mathrm{O}_{3}$ TiN-coated tool [49]. Similar results were reported in Thakur and Gangopadhyay [43] and Fan et al. [50]. Also, the main manifestation of tool wear is caused by the weakening of tool strength with the fusion between the workpiece and tool atoms at the tool-chip interface, based on an established model using a silicon carbide tool to cut Ni-based superalloys, and consideration of the Morse potential energy function between different atoms [51].

\subsubsection{Tool materials}

A coated carbide tool provides a longer tool life than an uncoated tool generally due to better wear resistance, which is however not always true if an improper coating and an improper condition are applied. A GC3015 grade coated tool did not show a better performance than an uncoated tool in terms of tool life at different cutting speeds and feed rates, unless depth of cut exceeded $1.0 \mathrm{~mm}$ [52]. Jawaid et al. [53] compared a PVD-coated and an uncoated tool in terms of tool wear and performance, the results of which indicated that the uncoated tool had a better chipping resistance at a lower cutting speed $25 \mathrm{~m} / \mathrm{min}$, while the TiN PVD-coated tools showed that better performance could be obtained at a higher speed, $50 \mathrm{~m} / \mathrm{min}$, due to the high wear resistance and low thermal conductivity of the coating materials. Similarly, Bhatt et al. [49] reported the best wear resistance at a higher speed, $100 \mathrm{~m} / \mathrm{min}$, by using a $\mathrm{TiCN} / \mathrm{Al}_{2} \mathrm{O}_{3} / \mathrm{TiN}$-coated tool
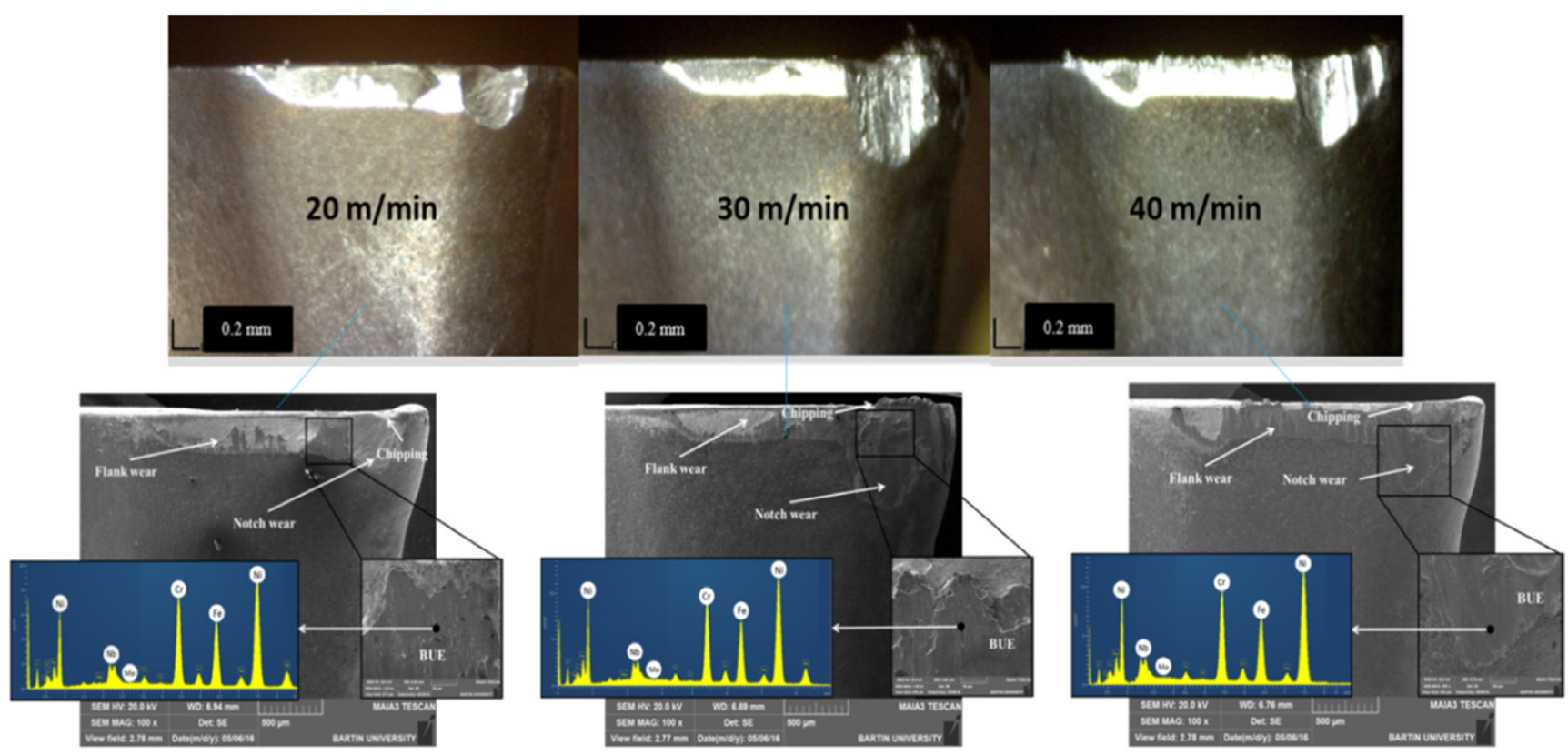

Fig. 4 Tool failure patterns in milling of Ni-based superalloys [48] 
and a better performance at a lower speed, $50 \mathrm{~m} / \mathrm{min}$, by applying an uncoated tool. Also, in terms of white layer thickness, a TiN/TiCN $/ \mathrm{Al}_{2} \mathrm{O}_{3} / \mathrm{ZrCN}$ CVD-coated carbide tool exhibited the advantage at a low and medium cutting speed, compared with an uncoated carbide particularly [54].

Cutting performance of a coated tool with good fitness for workpiece material can be enhanced dramatically. Sharman et al. [46] found that the tool coating was a major factor improving tool life up to $45 \%$ by using a TiAlN tool and a CrNcoated carbide tool used in a milling test. Similarly, a $\mathrm{TiCN} / \mathrm{AlO}_{3} / \mathrm{TiN}$-coated carbide provided $100 \%$ longer tool life than that of an uncoated tool material in machining of Inconel 718 [55]. In terms of tool wear, an AlTiN coating provided the best performance in machining of Inconel 718 as compared with an uncoated carbide [43].

A proper coating material can improve tool performance significantly in terms of tool wear resistance, and tool coatings have therefore been compared. A TiAlN-coated ball nose end mill performed better than a CrN-coated one in dry milling of Inconel 718, and the TiAIN coating could provide higher oxidation resistance, higher hardness, and a lower coefficient of friction [56]. Several coating materials, a $\mathrm{TiCN} / \mathrm{Al}_{2} \mathrm{O}_{3} / \mathrm{TiN}$ (CVD), a TiN/AlN superlattice (PVD), and a TiAlN (PVD), were compared experimentally in high-speed turning of Inconel 718 under MQL by Kamata and Obikawa [57]. The experimental results showed that the $\mathrm{TiCN} / \mathrm{Al}_{2} \mathrm{O}_{3} / \mathrm{TiN}$ under MQL cutting exhibited the longest cutting length at a cutting speed of $60 \mathrm{~m} / \mathrm{min}$. Compared with a TiAlN $+\mathrm{WC} / \mathrm{C}$ and a TiAlN $+\operatorname{MoST}\left(\mathrm{MoS}_{2}+\mathrm{Ti}\right)$, an AlTiN coating provided the best tool wear resistance in machining of Inconel 718 by Devillez et al. [44]. The tool coated with the PVD nanocomposite coating outperformed the AlTiN benchmark coated tool for the cutting speed greater or equal to $80 \mathrm{~m} / \mathrm{min}$ [58]. An adaptive AlTiN/MexN PVD nano-multilayered coating was proposed by Biksa et al. [59], and it showed better wear resistance performance in machining of Inconel 718 compared with nano-layered AlTiN coatings. Several nanomultilayered TiAlCrSiYN/TiAlCrN coatings were tested by Fox-Rabinovich et al. [60], and they provided a significant tool life improvement in machining of Inconel 718. In their follow-up work, an AlTiN/Cu coating showed multifunctionality including self-lubricating behavior which could reduce the thermal conductivity [61].

Coating methods and treatment have been focused on to improve tool quality. Several coating methods, PVD arc ionplating, PVD sputtering, PVD hollow cathode method, and CVD, were compared in machining of superalloys by Koseki et al. [63]. Their results showed that the PVD-sputtering and the CVD methods exhibited the fewest defects (droplet formation), and indicated the lightest flank wear. Then, in their other work, destruction and plastic deformation were found as the major reasons to cause the defects of the PVD arc ion-plating TiN coating (e.g., droplets and voids) at the starting point of damage
[62]. The results showed that defects adhered physically or mechanically to the cutting edge affected tool, rather than chemically, as shown in Fig. 5. Moreover, a cryogenic heat treatment could improve the adhesion of the hard coatings including the substrate material [48]. Compared with the multilayer nanocomposite hard coating carbide cutting tool at cutting speed $30 \mathrm{~m} / \mathrm{min}$ in milling of superalloys, the proposed treatment prolonged the tool life which was obtained by uncoated, TiN-, NC-, and TiAlN-coated ones, by 54\%, $110 \%, 29 \%$, and $30 \%$, respectively. In addition, a thinner PVD TiN coating generated less damage morphology compared with a thicker one in interrupted machining of superalloys [45].

\subsubsection{Tool geometry}

Tool geometry research is another important topic to tool performance. In general, the manufacturing process of a carbide tool refers to include mixing, pressing, sintering, processing (grinding), and coating. Here, carbide insert allows a complex geometry, e.g., chip breakers with curved surfaces.

There have not been many reported publications related to the cutting tool geometry. Tool angle selection is an important factor. Differently geometrical tools were selected in terms of residual stress, sensitive to the tool parameters [64]. In their experiment, a round shape carbide insert with chamfered cutting edge, negative rake angle, and small nose radius $(0.8 \mathrm{~mm})$ generated a small value of residual stress. Side cutting edge angles of two coated carbides were tested in turning of superalloys by Rahman et al. [18], and tool life was significantly prolonged with increasing the side cutting edge angles from $-5^{\circ}$ to $15^{\circ}$ and $45^{\circ}$. Increasing side cutting edge angle $k_{r}$ diminished the cutting aggressiveness, which was observed in [65]. Rake angle and edge radius have been considered in terms of cutting forces and serrated chip formation in orthogonal cutting of Inconel 100 by Ozel and Ulutan [66]. In their results, a positive rake angle and a larger edge radius generated higher specific cutting forces, and the degree of segmentation was mainly affected by the tool edge radius (decreases with increasing edge radius) and slightly affected by the tool rake angle. In addition, cutting edge curve was the focus of Tsai and Hsieh [67]. In their research, an S-type tool was designed and tested in a set of Taguchi milling experiments of superalloys, and the tool was experimentally validated suitable for high-speed and high-feed parameters.

\subsubsection{Coolant and machining condition}

Coolant is also associated with the cutting tool, and generally its types refer to normal wet, dry, MQL, HPC, and cryogenic types.

Dry machining is considered as environment-friendly. Devillez et al. [68] found that cutting forces generated under wet and dry conditions were at a similar level; however, a 


\section{Coatings prepared for each tools \\ $1 \mu m$ \\ Damage area of cutting edge for each coated cutting tool \\ (cutting length $\mathrm{L}=10 \mathrm{~m}$ )}
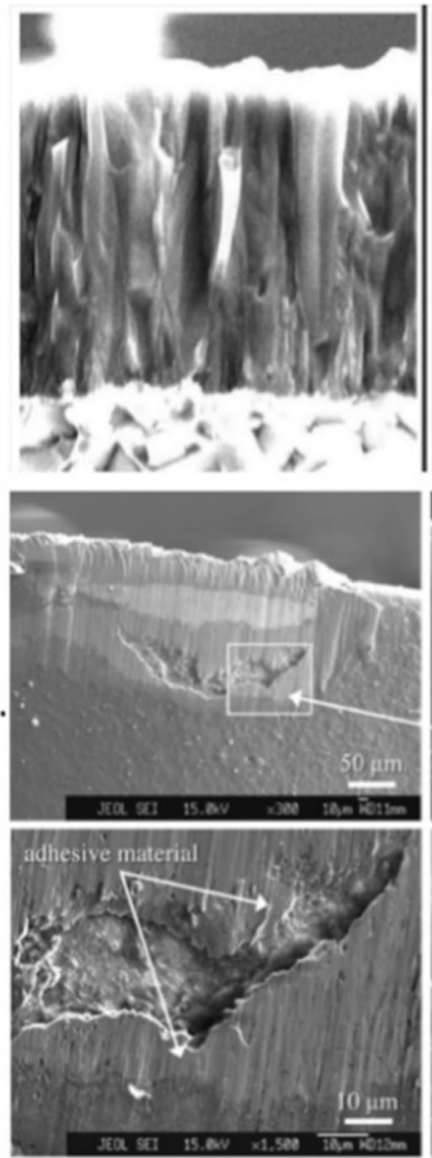

Cross-section of each coating on the cutting edge

(cutting length $\mathrm{L}=1 \mathrm{~m}$ ).

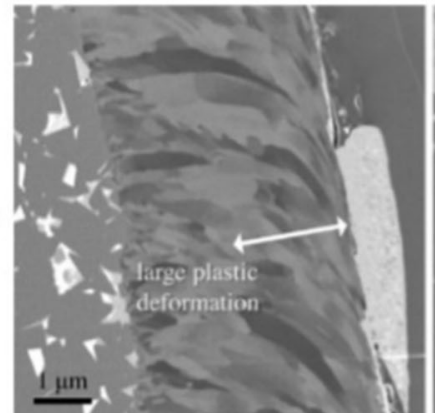

(a) TiN-Arc
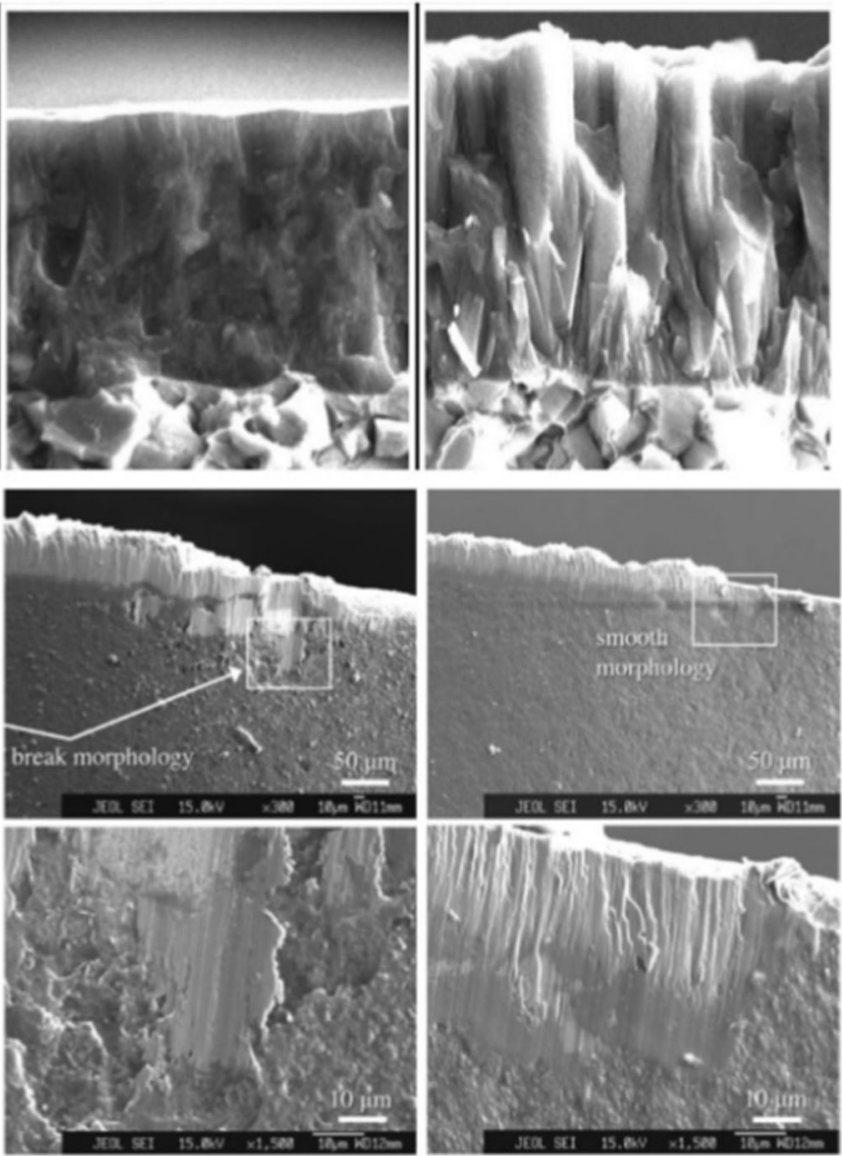

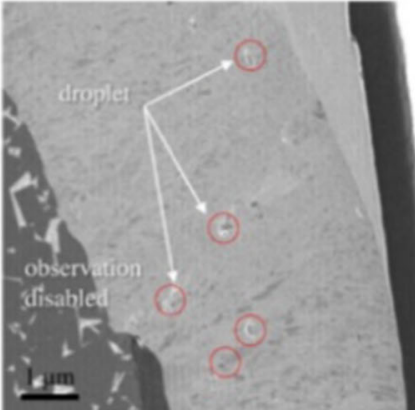

(b) $\mathrm{AlCrSiN}-\mathrm{Arc}$

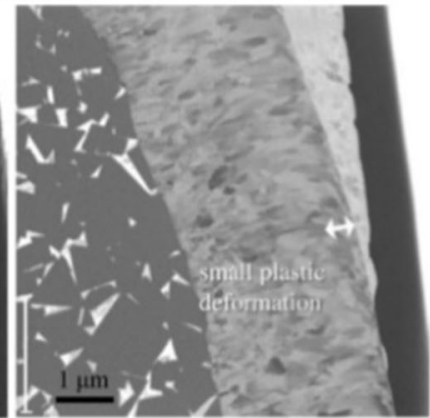

(c) AlCrSiN-SP

Fig. 5 Comparison of coated carbide cutting tool in cutting Inconel 718 [62]

BUE was observed on the machined surface in dry machining. Moreover, Zhang et al. [69] found that the tool life in an MQL was 1.57 times longer than that in dry machining. Cryogenic, dry, and MQL conditions were compared by using a carbide tool in the machining of Inconel 718 by Kaynak [70], the experimental result of which showed that flank face wear was lower under cryogenic condition; however, there was no significant influence on tool notch wears, as shown in Fig. 6. In addition, steady wear was easily achieved in milling, in which a self-organization dissipative structure was likely formed [71]. In comparison, MQL is more effective than cryogenic machining in reducing cutting tool wear, and the increment of feed rate increases the force, surface roughness, and tool wear using MQL on computerized numerical control (CNC) turning of 617 alloys [58, 72].

HPC is a good candidate coolant for machining of superalloys w.r.t. the improvement of chip breakage. Ezugwu and Bonney [73] experimented with the HPC machining of Inconel 718 by using a coated carbide, the result of which showed that the tool life was prolonged by increasing the coolant pressure and an ideal "C" shape chip was obtained under 203 bar. A HPC condition provided a textured surface carbide tool with a $45 \%$ reduction of flank wear compared with a normal tool [74]. 
Fig. 6 Comparison of coolants in machining of Inconel 718 [70]. a Flank face wear $\mathrm{V}_{\mathrm{B}}$. b Notch wear $\mathrm{V}_{\mathrm{N}}$

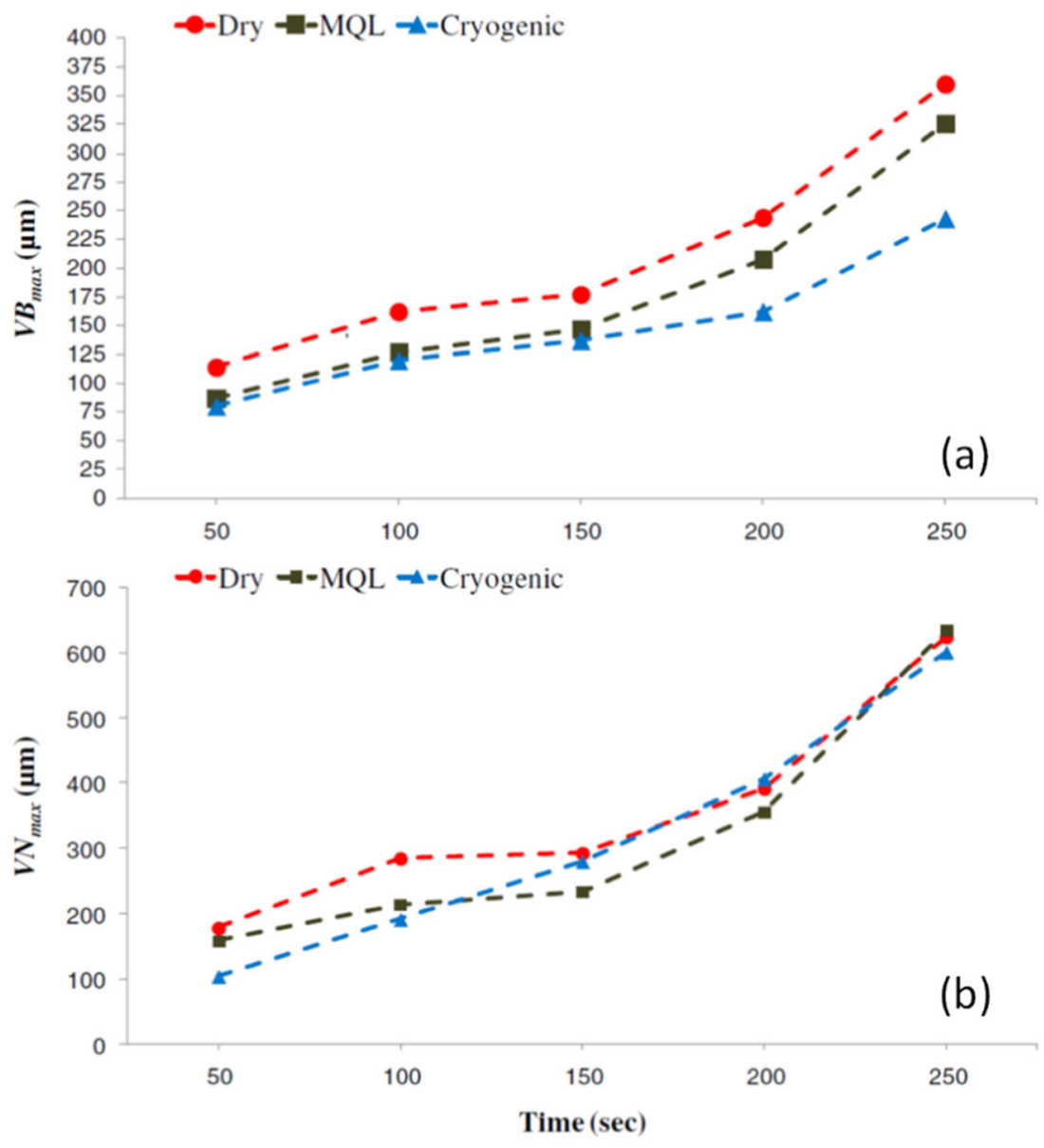

A laser-assisted HSM under dry condition was tested by using coated carbide tools (single-layer TiAIN PVD and triple-layer ( $\left.\mathrm{TiCN} / \mathrm{Al}_{2} \mathrm{O}_{3} / \mathrm{TiN}\right) \mathrm{CVD}$ ), considering a purely dry condition does not fit in machining of superalloys [75]. Their results showed that cutting force was reduced significantly, the surface finish was also improved by more than $25 \%$, and the material removal rate was increased by approximately $800 \%$ compared with conventional machining. Kong et al. [76] tested a laser-assisted milling in the machining of $\mathrm{K} 24$, a cast Ni-based superalloy, and found that a temperature above $800{ }^{\circ} \mathrm{C}$ could provide a $30-70 \%$ reduction of cutting forces and a lower tool wear compared with the conventional method. Abhishek et al. [77] adopted micro-abrasive blasting (MAB) for surface modification to enhance the performance of the cutting tool. The results indicated that the effectiveness of the MAB as a surface treatment technique can improve the wear performance of the cutting tools during the machining of the Ni-based superalloy.

In summary, tool failure pattern is not always stable against a certain tool material, tool geometry, and a combination of cutting parameters. Reducing a certain tool failure is a goal for the development of tool material and geometry, resulting in the worsening of other types of tool failure. Therefore, it is always a trade-off among the tool failures. Tool material research has been quite active in terms of publications compared with the research on tool geometry which is rarely reported. Here, coated carbide tools are the majority because of the excellent balance between cost and performance, ranging from a single layer to multilayers and from macroscale to nanoscale. HPC and cryogenic coolant conditions could improve tool life and chip breaking.

\subsection{Ceramics}

Ceramic tool has been used in machining of superalloys associated with HSM for almost 30 years since it was first reported [78].

\subsubsection{Tool failure}

Notch wear was found as a major failure pattern when a ceramic tool was first presented in an experiment of a Ni-based superalloy machining [78]. Serious boundary notch wear was found, which was mainly caused by an abrasive mechanism rather than by a thermally activated one [79]. Apart from notch wear, nose wear and flank face wear were identified 
as other dominant failure patterns of a $\mathrm{Si}_{3} \mathrm{~N}_{4}$ and an $\mathrm{Al}_{2} \mathrm{O}_{3^{-}}$ based ceramics, respectively [80]. Moreover, in dry turning of Inconel 718 , notch wear and flank wear were the main failure patterns in which the hardened layer was identified as the major reason [81].

Tool failure of a ceramic tool is strongly linked to cutting parameters. At cutting speeds of 200-400 and 400-700 $\mathrm{m} / \mathrm{min}$, the notch wear and the trailed edge wear were the major wear patterns, respectively, in milling of Inconel 718 by a whisker-reinforced ceramic tool [82]. A SiC whisker tool delivered the best notch wear resistance at $100-300 \mathrm{~m} / \mathrm{min}$ cutting speed, and a TiC added $\mathrm{Al}_{2} \mathrm{O}_{3}$-based ceramic tool showed better wear resistance at $500 \mathrm{~m} / \mathrm{min}$ cutting speed [83]. In addition, oxygen- and argon-rich atmospheres slowed/suppressed significantly notch wear of a SiAlON ceramic tool, regardless of tool geometry and cutting speed. However, they did not demonstrate a significant influence at a high speed [84].

In terms of wear mechanisms, abrasion and adhesion were the major reasons of ceramic cutting tools at a cutting speed of $120-300 \mathrm{~m} / \mathrm{min}$ in machining of Inconel 718 by using a $\mathrm{Si}_{3} \mathrm{~N}_{4}$ and an $\mathrm{Al}_{2} \mathrm{O}_{3}$-based ceramics [80]. Their results demonstrated that abrasion manifested itself in nose/flank face wear and notch wear of the two ceramics, and occurred on the $\mathrm{Si}_{3} \mathrm{~N}_{4}$ at a higher speed. Moreover, abrasive/adhesion was the main failure mechanism of a SiAlON whisker and a $\mathrm{SiC}$ whisker reinforced $\mathrm{Al}_{2} \mathrm{O}_{3}$ inserts in the milling of a $\gamma^{\prime}$ Ni-based superalloy [85]. Peng et al. [86] proposed the periodic boundary and three-body abrasion methods, and then a thermal-mechanical coupled model was established to describe the tool-chip tribology behavior and reveal the crack propagation process. The wear mechanisms for ceramic tools demonstrated a mixture effect of abrasive, adhesive, diffusive, and chemical wear. Diffusive wear mainly occurred in their flank faces; however, it did not constitute the main mechanism of notch wear, and chemical wear proved to be a key reason for notch wear at higher temperatures [87].

\subsubsection{Tool material}

Reinforcement material is an important consideration to the ceramic tool performance. Several $\mathrm{Al}_{2} \mathrm{O}_{3} / \mathrm{TiB}_{2} / \mathrm{SiC}$ ceramic cutting tools with different volume fractions of $\mathrm{TiB}_{2}$ particles and $\mathrm{SiC}$ whiskers were used in machining of Inconel 718 [88]. Their results indicated that fracture toughness and hardness of the composite tool materials continuously increased with increasing the $\mathrm{SiC}$ content from 5 to 30 vol.\%, as shown in Fig. 7. Coating can provide an improvement for a ceramic tool, and a set of $20 \%$ $\mathrm{SiC}$ whisker-reinforced $\mathrm{Al}_{2} \mathrm{O}_{3}$ tools coated by $\mathrm{CrN}$ and TiAlN using PVD were tested in machining of superalloys [89], the results of which showed that the coating provided a thermal barrier effect for the cutting tools, rather than a mechanical protection.

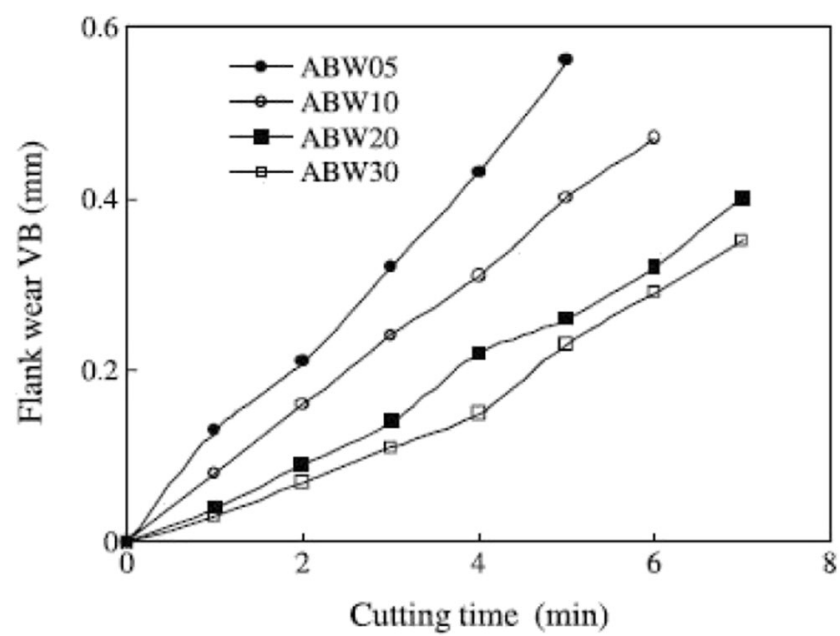

Fig. 7 Flank wear of $\mathrm{Al}_{2} \mathrm{O}_{3} / \mathrm{TiB}_{2} / \mathrm{SiC}$ ceramic tools with different $\mathrm{TiB}_{2}$ and $\mathrm{SiC}$ content in machining of Inconel 718 [88]. Cutting speed: 100 $\mathrm{m} / \mathrm{min}$; depth of cut: $0.3 \mathrm{~m}$; feed rate: $0.15 \mathrm{~mm} / \mathrm{rev}$

\subsubsection{Tool geometry}

Apart from the complex carbide geometry (Section 4.1.3), the tool geometry of a ceramic tool is limited due to the material properties. Therefore, the majority of research has been focused on cutting edge shape. Round shape inserts of a whisker-reinforced ceramic provided better performance compared with square ones in a milling experiment of Inconel 718 [82]. In another experiment [83], the less notch wear on the end flank face was found, as well as a lower thrust force, as shown in Fig. 8. Bigger contact radius of a $\mathrm{SiC}$ whiskerreinforced $\mathrm{Al}_{2} \mathrm{O}_{3}$ ceramic tool provided a lower surface roughness under HPC in the machining of Inconel 718 [90]; however, the coolant accelerating notch wear on both flank and rake faces was observed.

In summary, the failure of the ceramic tool refers to notch wear, boundary notch wear, nose wear, and flank wear in the machining of superalloys. Less work has been focused on tool geometry and tool material. In addition, a proper coolant condition could prolong tool life. Flank wear was reduced by 50 $65 \%$, and surface roughness was reduced by $39-51 \%$ under atomization-based cutting fluid (ACF) due to solid lubricants at a tool-chip interface limiting notch wear and fracture of tool edge [91].

\subsection{Polycrystalline cubic boron nitride (PCBN)}

PCBN cutting tools have been extensively applied to the machining of high-hardness (50-70 HRC) steel since it can provide a quite great machined surface. Considering the required properties of tool materials for the machining of Ni-based superalloys, theoretically, PCBN offers a great advancement since it is equipped with an excellent hardness at high temperatures. PCBN was first introduced to the machining of 


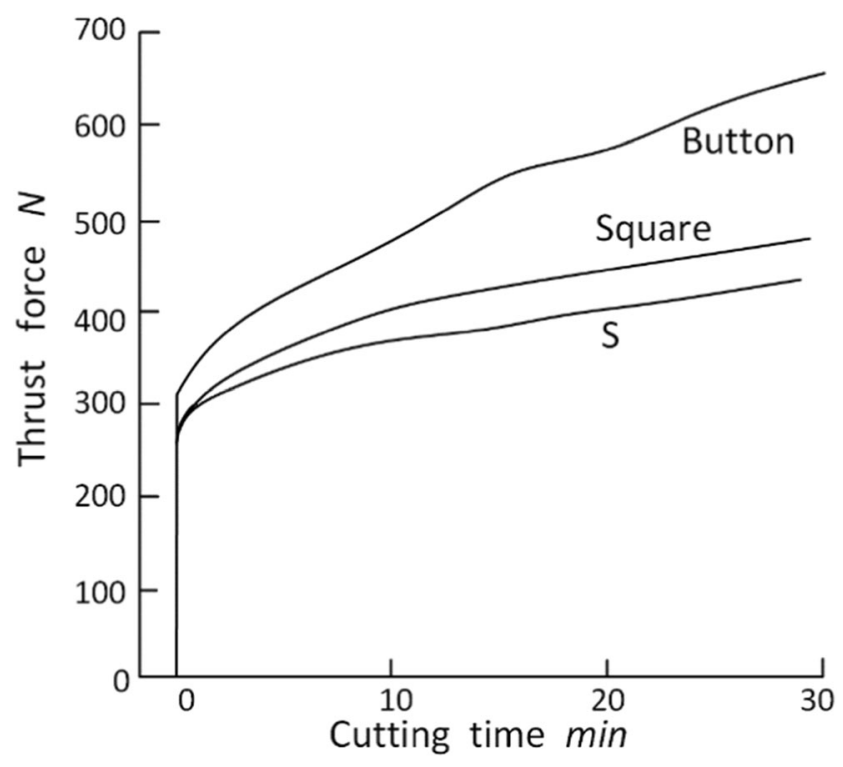

Fig. 8 Thrust force in machining of Inconel 718 with $\mathrm{Al}_{2} \mathrm{O}_{3} / \mathrm{TiC}$ ceramic tool having different shapes of cutting edge [83]

superalloys in 1978 by Focke et al. [92]. Their results showed great potential of PCBN in the machining of superalloys. However, its tool cracking due to its high brittleness and chip breaking difficulty owing to no chip breaker are the two major issues of a PCBN cutting tool.

\subsubsection{Tool failure}

BUE and flank wear were found as the major tool failure patterns in the machining of a Ni-based superalloy GH4169 (equivalent to Inconel 718) [3]. Several tool wear patterns of PCBN were identified and summarized according to the wear positions [93], i.e., the main edge and its border, the vice edge and its border, and the middle between the two edges, as shown in Fig. 9. The major mechanisms causing the PCBN tool were adhesion, diffusion, chemical, and their combinations, which was found experimentally by Costes et al. [94] and Bushlya et al. [95].

\subsubsection{Cutting chip}

Chip breaking problem was highlighted owing to the lack of chip breaker in the machining of superalloys, as shown in Fig. 10, e.g., unbroken chip causes tool breakage and shortens tool life [96]. In another experiment, a number of burrs were found in the machining of GH4169, and the burrs could provide an additional connection between the machined surface and the generated chips, which may be a reason leading to the chip breaking difficulty [97]. Moreover, chip macro cross-section has been focused on. The mechanisms of the serrated chip formation in a highspeed turning of Inconel 718 was investigated by Pawade and Joshi [98]. They discovered that the pitch of the serrated teeth on chips was changed periodically after every 3-4 teeth along the chip length. Based on a set of turning experiments of a Ni-based superalloy, GH706, serrated chip parameters were connected with the formation of the serrated chip quantitatively [99].

\subsubsection{Tool material}

CBN content, grain size, and binder type of PCBN materials have a critical influence on the cutting performance, e.g., tool wear resistance. A low CBN content between 45 and $60 \%$ of a cutting tool with a ceramic binder showed better wear resistance in a turning experiment of Inconel 718 [94]. However, sometimes, the influence of CBN content on tool wear is also

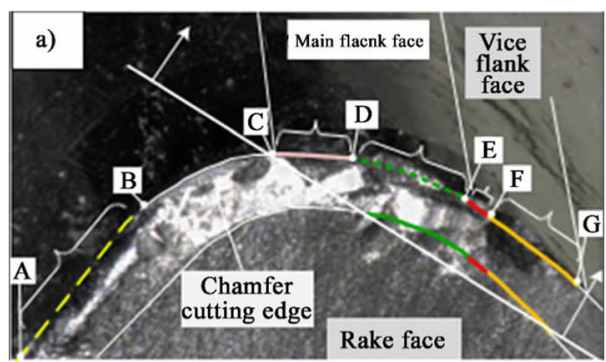

PCBN insert
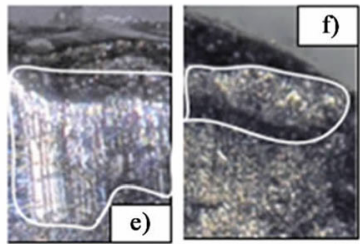

E-F: Intersection of main and vice cutting edge

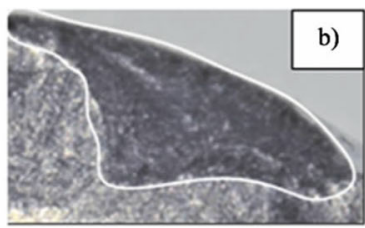

C-D: Main cutting edge border
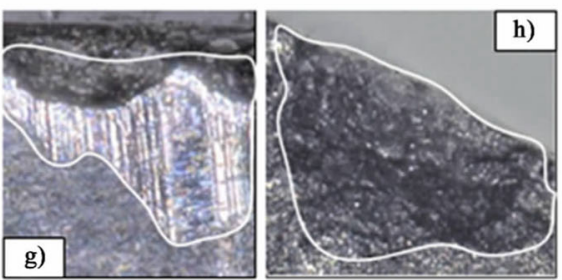

F-G: Vice cutting edge
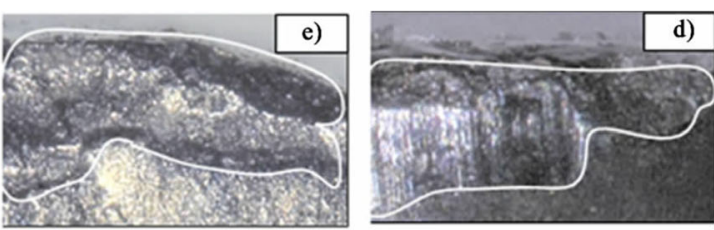

D-E: Main cutting edge

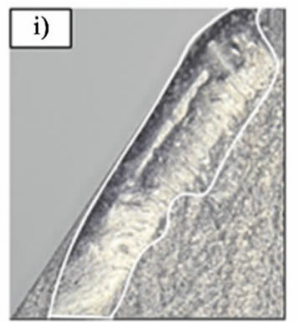

A-B: Edge without cutting

Fig. 9 a-i Tool wear patterns of PCBN in machining of Ni-based superalloys [93] 


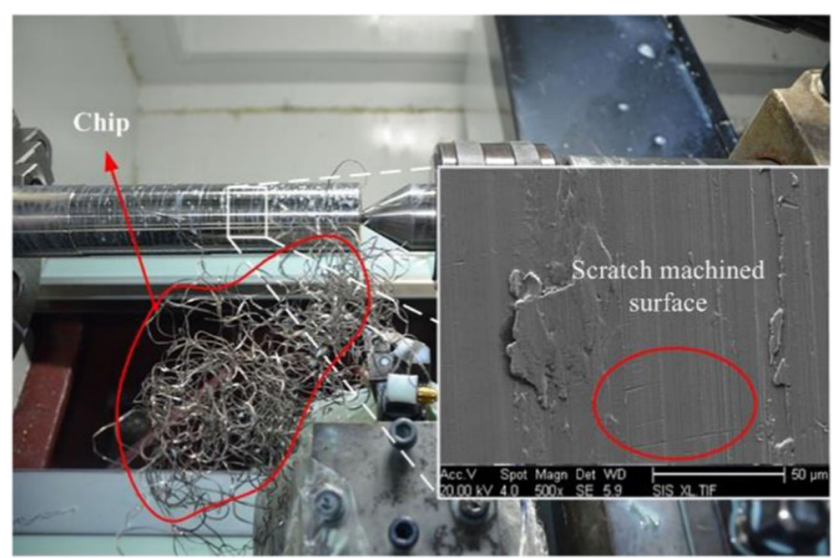

Fig. 10 Cutting chip and surface damage in turning of superalloys under normal cooling [96]

related to the types of Ni-based superalloys. In another turning experiment of superalloys GH706 (39-44\% Ni), the highest $\mathrm{CBN}$ content tool with metal binder showed the best tool wear resistance within five types of PCBN materials with different CBN contents and binders. Nowadays, coating technology can be applied to a PCBN tool. A coated tool and an uncoated PCBN tool were compared in a set of turning experiments of Inconel 718 by Bushlya et al. [100], the results of which showed that the employed TiN coat could prolong the tool life by $20 \%$. However, only a limited cutting speed could be used due to chemical wear at higher speed. Then they concluded that workpiece elements diffused into the PCBN tool [95], where results of energy-dispersive X-ray (EDX) and atomic force microscopy (AFM) analyses suggested the dominance of chemical and abrasive wear mechanisms. Niobium and molybdenum of a superalloy had been found to have a relation with the chemical wear of a PCBN [101].

\subsubsection{Tool geometry}

Similarly, with the research on the tool geometry of the ceramic tool (Section 4.3.3), tool geometries of PCBN tools are not as complex as the carbide tool (Section 4.2.3) due to the differences of material properties and manufacturing processes. Therefore, only the edge shape and limited angles have been focused on. Two shapes of PCBN inserts, i.e., a rhomboid tool and a round tool, were compared in turning of Inconel 718 by Khan et al. [102]. They found that the tool life of the round tool was significantly longer than the rhomboid one at a lower cutting speed, $150 \mathrm{~m} / \mathrm{min}$, and that there was no difference found at higher cutting speeds, 300 and $450 \mathrm{~m} / \mathrm{min}$. To better understand the relationship between tool geometrical parameters and tool performance, a grooving-based experimental approach was proposed [19]. Compared with turning-based methods, the proposed method allowed the targeting performance indexes, e.g., cutting force and chip breaking, to be linked with tool angles, e.g., rake angle, flank angle, and cutting-edge angle. The experimental results demonstrated that the tool fraction was sensitive to chamfer width and rake angle at the radius direction, cutting force was sensitive to the entering angle, and the chip control was sensitive to the flank angle.

\subsubsection{Coolant condition}

Coolant condition has attracted research interests when considering both the advancement and drawbacks of a PCBN tool. Dry and wet coolants were tested at low-level and high-level cutting speeds, the results of which demonstrated that the wet coolant could significantly reduce tool wear and cutting edge chipping [103]. Considering the big benefit of dry machining of hardened steels by PCBN, Cantero et al. [104] proposed a high-speed finish turning of Inconel 718 by using four types of PCBN tools under dry condition. Their results showed that the strategy was not industrially viable due to the short tool life. A spray mode of cutting fluid with compressed air, like an MQL, was proposed in machining of Inconel 783 by Tazehkandi et al. [105], in which biodegradable vegetable oil improved the cooling capacity compared with conventional cutting fluid. In addition, given the benefit for chip breaking under HPC, it was used in the turning of superalloys by PCBN, the results of which showed that tool wear was reduced significantly and chip breaking was much easier compared with a normal coolant [96].

In summary, BUE and flank wear are the dominant failure patterns of the cutting tool, which is however not always consistent. Chip breakage is a major issue due to no chip breaker on the PCBN tool. They are related to tool geometry and material, as well as cutting parameters (e.g., cutting speed and depth of cut). However, almost all reported factors are not independent. In addition, the HPC coolant could be a solution for supporting chip breaking.

\section{Recap on tool technologies in machining of superalloys}

From the current status of the related work in Section 4, there are several found trends of cutting tool research in the machining of Ni-based superalloys.

1. Carbide tool research is more active than ceramic and PCBN tools:

- Coated carbides have been reported more frequently than uncoated carbides, ceramics, and PCBNs since they possess an extremely good balance between cost and cutting performance.

- Coating material researches have been developed from a microscopic scale to a nanoscale. 
2. The performance of the cutting tool, including tool failures, chip breaking, and machining quality, is influenced by tool geometry, and dependent on tool material and machining condition. Therefore, researching each topic individually may not work properly in real applications.

3. Research on the design methods of the cutting tool has been rarely reported, and cutting tool optimization should be considered as a part of process planning.

According to the observed trends, this section is devoted to some open issues of tool technologies in machining of superalloys, i.e., cutting tool design, tool coating, HSM, and HPC.

\subsection{Cutting tool design}

Since cutting tool design has been considered as a standard machining resource and a pure application issue, the related work has been done mainly by tool manufacturers. Tool users only select cutting tools, which causes a loss of solution space regarding the cutting tool parameters of materials and geometries. Moreover, the optimization of cutting tool parameters has been done case by case, which highly relies on the experiments, generating the unacceptable differences between end users and in-house testing. Nevertheless, systematic research on cutting tool design was performed a few years ago [39, 41]. Shape (including geometry and material), cutting performance, and application for a cutting tool were considered for a while; however, it is still far from real industrial applications due to the lack of data support.

On the other hand, a well-designed chip breaker and innovative tool geometry with the best fitness for machining of superalloys can improve the tool performance significantly. However, the research on cutting tools in machining of superalloys has not attracted enough interest in recent years, including innovative tool geometry and chip breaker.

\subsection{Tool coating}

Coatings can enhance the tool wear resistance to abrasion, erosion, galling, and fretting. Although coating cost increases, coating could provide much more benefit due to tool performance improvement. Coated carbides have been frequently used, and the coating materials include $\mathrm{TiN}, \mathrm{TiCN}, \mathrm{Al}_{2} \mathrm{O}_{3}$, $\mathrm{ZrCN}$, and their combinations. Moreover, several nano multi-layer coatings, including TiAlN + MoST $\left(\mathrm{MoS}_{2}+\mathrm{Ti}\right)$ and TiAlCrSiYN/TiAlCrN, have also been investigated. Furthermore, an enriched coating with self-lubricating function, $\operatorname{AlTiN} / \mathrm{Cu}$, has been introduced, and in general, they have provided enhanced functionality compared with the normal coatings. During the development, a clear trend could be observed that coatings were developed from a single layer to multilayers, from macroscale to nanoscale, and from a single function to multifunction. Therefore, coating types and processing technologies remain important topics for research and development of a cutting tool.

\subsection{High-speed machining (HSM)}

Ceramic and PCBN cutting tools provide a considerable high hardness at high temperatures so that they can often be used in HSM of superalloys which is often in a high cutting temperature. High cutting efficiency and high surface quality are the two greatest advancements for HSM. However, the determination of cutting speed should consider cutting tool failures since the dominant failure patterns are related to cutting speed, which was observed in machining of superalloys by using the ceramic tool. In addition, the robustness of HSM is not as high as normal machining in terms of machining quality and tool wear. Therefore, the relevant research on these topics should be focused on constantly.

\subsection{High-pressure coolant (HPC)}

HPC provides two major benefits generally, i.e., lowering the cutting temperature and assisting the chip breaking. The former contributes to reducing the tool wear of carbide significantly. The latter provides an additional "breaker," especially for ceramic and PCBN tools which are not normally equipped with chip breaker, leading to enhanced applicability of ceramic and PCBN tools in industries. However, issues in the machining under HPC have not been fully addressed, e.g., influence on surface quality and tool wear, especially for PCBN tools; therefore, the relevant topics should be focused on toward HPC in industries.

\subsection{Statistical analysis}

There are 117 published papers from 1957 to 2020, including 105 journal papers, 8 conference papers, and 5 books/theses. Within journals, International Journal of Advanced Manufacturing Technology, Journal of Materials Processing Technology, and Internal Journal of Machine Tools and Manufacturing are the three major journals publishing the researches on cutting tool technology, and include 16 (15.10\% in journal papers), 11 (10.38\% in journal papers), and $9(8.49 \%$ in journal papers) publications, respectively. In addition, there are other journals publishing more than one, i.e., Wear (8), CIRP Annals-Manufacturing Technology (6), Machining Science and Technology (4), Tribology International (4), Chinese Journal of Mechanical Engineering (3), Key Engineering Materials (3), Ceramics International (2), Journal of Cleaner Production (2), Proceedings of the Institution of Mechanical Engineers, Part B: Journal of Engineering Manufacture (2), Tribology Transactions (2), Advanced Materials Research (2), Journal 
Fig. 11 Total number of publications of cutting tool technology in machining of superalloys over the years from 1957 to 2020

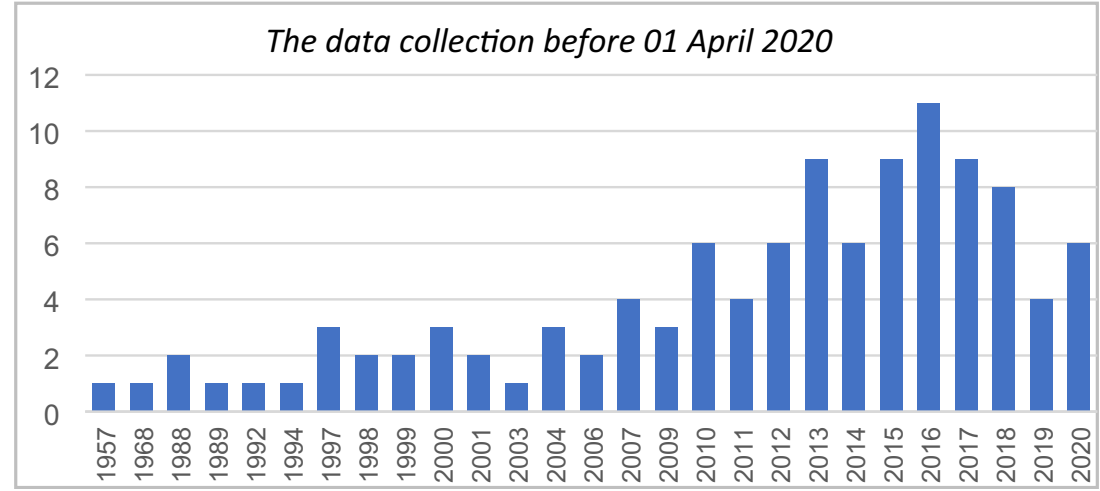

of Manufacturing Science and Engineering (2), and Journal of Intelligent Manufacturing (1).

Figure 11 shows the total number of the research publications of cutting tool technology from 1957 to 2020 . The publications are less than six per year before 2012, and then they were increased from 2013 , and 63 papers $(53.85 \%$ in publications) were reported from 2013 to 2020.

\section{Conclusions and future trends}

Whereas the previous sections may help predict foreseeable future research directions for cutting tool technology in machining of Ni-based superalloys, it is never an easy task to do so in any capacity although the machining has been developed for more than 100 years. This review paper is only based on the published articles, rather than practically applied methods

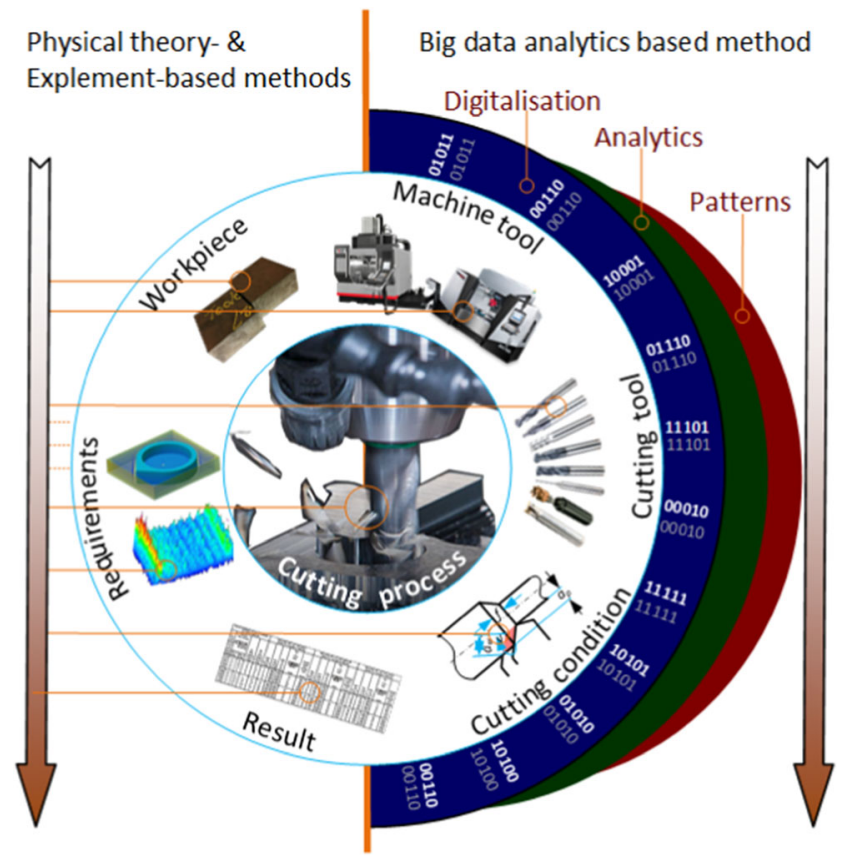

Fig. 12 Differences between big data analytics and conventional methods used in real industry. Since the materials of the industry are not available to the authors, the used methods in the tooling companies are not reviewed in this paper. To the best understanding of the authors, the future trends can be identified in tool material, tool geometry, new method, functional surfaces, and data-driven approaches enabling global optimization.

\subsection{New tool materials, tool geometries, and new machining methods}

Big data with advanced analytics can only be used to improve the current machining methods, rather than replacing them. Big data analytics in machining relies on machining data; therefore, it does not work if the data are not available. Innovative methods/designs, however, can improve machining significantly. For example, a novel treatment, a premachining of an Al-Si workpiece before machining of Inconel 718, provided a $300 \%$ reduction of tool wear [106]. All-direction turning method, Prime Turning, has changed the single turning direction into two directions and improved machining efficiency significantly, which has re-defined the thinking of turning. ${ }^{2}$ Relevant data are not available before the method is applied in practice. In this case, new materials including tool coating, tool geometries, and new machining methods are still important to improve the existing cutting tool technologies, which brings the tool to a higher level.

\subsection{Functional surfaces on cutting tool}

Functional surfaces have attracted a large number of research interests. For example, textured cutting tools which can be machined by laser [107, 108] or grinding [109, 110] have shown a great potential in the process of machining, with improved cutting performance in terms of machining quality and tool life. The textures on the tool surface provided a significant improvement against tool wear in the machining of superalloys [74, 111]. From the reported articles, textures on

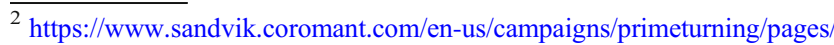
default.aspx
} 
the tool surface could change the status of wear and provide macro-pools for coolants. Regardless of the fact that the additional laser processing or grinding method may increase the cost of cutting tools, the benefits of the textured tools are more obvious in relation to the workpiece cost, especially in machining of Ni-based superalloys.

\subsection{Data-driven methods enabling comprehensive optimization of machining}

In recent years, data-driven methods have obtained much attention since they are able to handle high-dimensional datasets for highly non-linear machining applications involving multiresources, e.g., workpiece, cutting tools, and machining tools. Date-driven methods can solve the limited coverage problems which the conventional methods have. Also, a large number of materials are machined every day, which can provide big enough data source to mine the patterns in machining. To better use the potential of big data, a set of data-driven approaches have been proposed recently, e.g., tool wear prediction [112, 113] and tool wear evaluation [114].

The hidden patterns in big data enable a much-improved machining optimization when combined with analytics algorithms. By combining machining condition optimization, cutting tool design/selection, and machine tool selection as a whole, big data analytics has been applied to machining optimization [115-117]. In this way, the machining-related decision process can be transformed into a data problem, which could provide a global optimization for machining, as shown in Fig. 12.

However, there are many challenges of big data in machining:

1. Data quality is not high enough for data analytics, and there is no generic method to clean machining data.

2. Data in machining are from multiple sources, e.g., $\mathrm{NC}$ controller, sensors, and measurement machines, which makes data processing difficult.

3. How to represent machining resources digitally is still a question to reduce the hidden information of machining application; therefore, machining resource digitalization is the key to data-driven approaches.

Acknowledgments This research received support from the National Natural Science Foundation of China under Grant No. 51775024 and No. 51605121, as well as the MIIT (Ministry of Industry and Information Technology) Key Laboratory of Smart Manufacturing for High-end Aerospace Products Program of China.

Funding Open access funding provided by Royal Institute of Technology.

Open Access This article is licensed under a Creative Commons Attribution 4.0 International License, which permits use, sharing, adaptation, distribution and reproduction in any medium or format, as long as you give appropriate credit to the original author(s) and the source, provide a link to the Creative Commons licence, and indicate if changes were made. The images or other third party material in this article are included in the article's Creative Commons licence, unless indicated otherwise in a credit line to the material. If material is not included in the article's Creative Commons licence and your intended use is not permitted by statutory regulation or exceeds the permitted use, you will need to obtain permission directly from the copyright holder. To view a copy of this licence, visit http://creativecommons.org/licenses/by/4.0/.

\section{References}

1. Xu X, Wang L, Newman ST (2011) Computer-aided process planning - a critical review of recent developments and future trends. Int J Comput Integr Manuf 24:1-31. https://doi.org/10. 1080/0951192x.2010.518632

2. M'Saoubi R, Axinte D, Soo SL et al (2015) High performance cutting of advanced aerospace alloys and composite materials. CIRP Ann Manuf Technol 64:557-580. https://doi.org/10.1016/ j.cirp.2015.05.002

3. Ji W, Liu XL, Li HY et al (2013) Research of PCBN tool wear mechanism in turning Ni-based superalloy. Adv Mater Res 820: 185-189. https://doi.org/10.4028/www.scientific.net/AMR.820. 185

4. Childs THC, Maekawa K, Obikawa T, Yamane Y (2000) Metal machining: theory and applications. Butterworth-Heinemann

5. Ezugwu EO, Wallbank J (1988) Review of the manufacture and properties of ceramic cutting tools. Adv Mater Technol Monit:111

6. Wentorf RH Jr (1957) Cubic form of boron nitride. J Chem Phys 26:956

7. Ezugwu EO, Wang ZM, Machado AR (1999) The machinability of nickel-based alloys: a review. J Mater Process Technol 86:116. https://doi.org/10.1016/S0924-0136(98)00314-8

8. Ezugwu EO, Bonney J, Yamane Y (2003) An overview of the machinability of aeroengine alloys. J Mater Process Technol 134: 233-253. https://doi.org/10.1016/S0924-0136(02)01042-7

9. Arunachalam R, Mannan MA (2000) Machinability of nickelbased high temperature alloys. Mach Sci Technol 4:127-168. https://doi.org/10.1080/10940340008945703

10. Guo YB, Li W, Jawahir IS (2009) Surface integrity characterization and prediction in machining of hardened and difficult-tomachine alloys: a state-of-art research review and analysis. Mach Sci Technol 13:437-470

11. Ulutan D, Ozel T (2011) Machining induced surface integrity in titanium and nickel alloys: a review. Int J Mach Tools Manuf 51: 250-280. https://doi.org/10.1016/j.ijmachtools.2010.11.003

12. Thakur A, Gangopadhyay S (2016) State-of-the-art in surface integrity in machining of nickel-based super alloys. Int J Mach Tools Manuf 100:25-54. https://doi.org/10.1016/j.ijmachtools.2015.10. 001

13. Zhu D, Zhang X, Ding H (2013) Tool wear characteristics in machining of nickel-based superalloys. Int J Mach Tools Manuf 64:60-77. https://doi.org/10.1016/j.ijmachtools.2012.08.001

14. Akhtar W, Sun J, Sun P et al (2014) Tool wear mechanisms in the machining of nickel based super-alloys: a review. Front Mech Eng 9:106-119. https://doi.org/10.1007/s11465-014-0301-2

15. Liang X, Liu Z, Wang B (2019) State-of-the-art of surface integrity induced by tool wear effects in machining process of titanium and nickel alloys: a review. Measurement 132:150-181. https:// doi.org/10.1016/J.MEASUREMENT.2018.09.045 
16. Shokrani A, Dhokia V, Newman ST (2012) Environmentally conscious machining of difficult-to-machine materials with regard to cutting fluids. Int J Mach Tools Manuf 57:83-101. https://doi.org/ 10.1016/j.ijmachtools.2012.02.002

17. Mohsan AUH, Liu Z, Padhy GK (2017) A review on the progress towards improvement in surface integrity of Inconel 718 under high pressure and flood cooling conditions. Int J Adv Manuf Technol 91:107-125. https://doi.org/10.1007/s00170-016-9737-3

18. Rahman M, Seah WKH, Teo TT (1997) The machinability of Inconel 718. J Mater Process Technol 63:199-204. https://doi. org/10.1016/S0924-0136(96)02624-6

19. Ji W (2013) Tool design and performance evaluation of PCBN in cutting superalloys

20. Ezugwu EO, Wang ZM, Okeke CI (1999) Tool life and surface integrity when machining Inconel 718 with PVD- and CVDcoated tools. Tribol Trans 42:353-360. https://doi.org/10.1080/ 10402009908982228

21. Olovsjö S, Wretland A, Sjöberg G (2010) The effect of grain size and hardness of wrought Alloy 718 on the wear of cemented carbide tools. Wear 268:1045-1052. https://doi.org/10.1016/j. wear.2010.01.017

22. Hayama H, Kiyota H, Itoigawa F (2015) Size effect in machining on initial tool wear in heat-resistant alloy cutting. Key Eng Mater 656-657:357-362. https://doi.org/10.4028/www.scientific.net/ KEM.656-657.357

23. Thakur DG, Ramamoorthy B, Vijayaraghavan L (2009) Machinability investigation of Inconel 718 in high-speed turning. Int J Adv Manuf Technol 45:421-429. https://doi.org/10.1007/ s00170-009-1987-x

24. Lukshin VS (1968) Theory of screw surfaces in cutting tool design. Mach Moscow

25. Liu J (2005) Theory and practice of cutting tool precision design. National Defence Industry Press, Beijing

26. Benlahmidi S, Aouici H, Boutaghane F, et al (2016) Design optimization of cutting parameters when turning hardened AISI H1 1 steel (50 HRC) with CBN7020 tools Int J Adv Manuf Technol 118. https://doi.org/10.1007/s00170-016-9121-3

27. Ji W, Liu X, Wang L, Sun S (2015) Experimental evaluation of polycrystalline diamond (PCD) tool geometries at high feed rate in milling of titanium alloy TC11. Int J Adv Manuf Technol 77: 1549-1555. https://doi.org/10.1007/s00170-014-6517-9

28. Feito N, Diaz-Álvarez J, López-Puente J, Miguelez MH (2016) Numerical analysis of the influence of tool wear and special cutting geometry when drilling woven CFRPs. Compos Struct 138: 285-294. https://doi.org/10.1016/j.compstruct.2015.11.065

29. Chen D-C, You C-S, Kao S-H (2016) Finite element analysis of chip breaker geometry in turning process. Adv Mech Eng 8:1-10. https://doi.org/10.1177/1687814016659823

30. Zong WJ, Li D, Cheng K et al (2007) Finite element optimization of diamond tool geometry and cutting-process parameters based on surface residual stresses. Int J Adv Manuf Technol 32:666674. https://doi.org/10.1007/s00170-005-0388-Z

31. Ma J, Ge X, Duong NH, Lei S (2015) Numerical investigation of restricted contact cutting tool in machining of AISI 1045 steel. Int J Manuf Res 10:147-161. https://doi.org/10.1504/IJMR.2015. 069714

32. Yu M (2013) Parametric modeling on turning process and optimization control. Harbin University of Science and Technology

33. Yang WH, Tarng YS (1998) Design optimization of cutting parameters for turning operations based on the Taguchi method. $\mathrm{J}$ Mater Process Technol 84:122-129. https://doi.org/10.1016/ S0924-0136(98)00079-X

34. Lu Y, Zhu Y (1988) Expert system in the design of complex shaped tools. Tool Eng:1-4
35. Mizugaki Y, Hao M, Sakamoto M (1994) Optimal tool selection based on genetic algorithm in a geometric cutting simulation. 43: 433-436

36. Mukherjee I, Ray PK (2006) A review of optimization techniques in metal cutting processes. Comput Ind Eng 50:15-34. https://doi. org/10.1016/j.cie.2005.10.001

37. Ji W, Liu XL, Li K et al (2014) CSPAID: Cutting Tool "ShapePerformance-Application" Integrating Design Approach. Mater Sci Forum 800-801:470-474. https://doi.org/10.4028/www. scientific.net/MSF.800-801.470

38. Ji W (2015) Research on design and manufacturing of solid carbide ball end mill of "shape-performance-application" integration. Harbin University of Science and Technology (In Chinese)

39. Liu X, Ji W, Fan M, Wang C (2016) Feature based cutting tool "shape-performance-application" integrating design approach. Aust J Mech Eng 52:146-153 (in Chinese)

40. Ji W, Zhao Z, Liu X (2016) A GA-based optimization algorithm for cutting tool "shape-performance-application" integrated design approach. Procedia CIRP 56:90-94. https://doi.org/10.1016/ j.procir.2016.10.023

41. Ji W, Zhao Z, Liu X (2017) Tool shape-performance-application integrated design approach: a development and a numerical validation. Int J Adv Manuf Technol. https://doi.org/10.1007/s00170017-0105-8

42. Ezugwu EO, Pashby IR (1992) High speed milling of nickelbased superalloys. J Mater Process Technol 33:429-437. https:// doi.org/10.1016/0924-0136(92)90277-Y

43. Thakur A, Gangopadhyay S (2016) Influence of tribological properties on the performance of uncoated, CVD and PVD coated tools in machining of Incoloy 825. Tribol Int 102:198-212. https://doi. org/10.1016/j.triboint.2016.05.027

44. Devillez A, Schneider F, Dominiak S et al (2007) Cutting forces and wear in dry machining of Inconel 718 with coated carbide tools. Wear 262:931-942. https://doi.org/10.1016/j.wear.2006. 10.009

45. Koseki S, Inoue K, Uehara K et al (2015) Damage of PVD-coated cutting tools due to interrupted cutting of Ni-based superalloys. Key Eng Mater 657:191-197. https://doi.org/10.4028/www. scientific.net/KEM.656-657.191

46. Sharman A, Dewes RC, Aspinwall DK (2001) Tool life when high speed ball nose end milling Inconel 718 (TM). J Mater Process Technol 118:29-35. https://doi.org/10.1016/S0924-0136(01) 00855-X

47. Li HZ, Zeng H, Chen XQ (2006) An experimental study of tool wear and cutting force variation in the end milling of Inconel 718 with coated carbide inserts. J Mater Process Technol 180:296304. https://doi.org/10.1016/j.jmatprotec.2006.07.009

48. Kursuncu B, Caliskan H, Guven SY, Panjan P (2018) Improvement of cutting performance of carbide cutting tools in milling of the Inconel 718 superalloy using multilayer nanocomposite hard coating and cryogenic heat treatment. Int J Adv Manuf Technol:1-13. https://doi.org/10.1007/s00170-018-1931-z

49. Bhatt A, Attia H, Vargas R, Thomson V (2010) Wear mechanisms of WC coated and uncoated tools in finish turning of Inconel 718. Tribol Int 43:1113-1121. https://doi.org/10.1016/j.triboint.2009. 12.053

50. Fan Y, Hao Z, Zheng M et al (2013) Study of surface quality in machining nickel-based alloy Inconel 718. Int J Adv Manuf Technol 69:2659-2667

51. Hao Z, Cui R, Fan Y, Lin J (2019) Diffusion mechanism of tools and simulation in nanoscale cutting the $\mathrm{Ni}-\mathrm{Fe}-\mathrm{Cr}$ series of nickelbased superalloy. Int J Mech Sci 150:625-636

52. Choudhury IA, El-Baradie MA (1998) Machining nickel base superalloys: Inconel 718. Proc Inst Mech Eng B J Eng Manuf 212:195-206. https://doi.org/10.1243/0954405981515617 
53. Jawaid A, Koksal S, Sharif S (2001) Cutting performance and wear characteristics of PVD coated and uncoated carbide tools in face milling Inconel 718 aerospace alloy. J Mater Process Technol 116:2-9. https://doi.org/10.1016/S0924-0136(01) 00850-0

54. Thakur A, Gangopadhyay S, Maity KP (2014) Effect of cutting speed and tool coating on machined surface integrity of Ni-based super alloy. Procedia CIRP 14:541-545. https://doi.org/10.1016/j. procir.2014.03.045

55. Sharman ARC, Hughes JI, Ridgway K (2004) Workpiece surface integrity and tool life issues when turning Inconel $718^{\mathrm{TM}}$ nickel based superalloy. Mach Sci Technol 8:399-414. https://doi.org/ 10.1081/MST-200039865

56. Ng E-G, Lee DW, Sharman ARC et al (2000) High speed ball nose end milling of Inconel 718. CIRP Ann 49:41-46. https://doi. org/10.1016/S0007-8506(07)62892-3

57. Kamata Y, Obikawa T (2007) High speed MQL finish-turning of Inconel 718 with different coated tools. J Mater Process Technol 192-193:281-286. https://doi.org/10.1016/j.jmatprotec.2007.04. 052

58. Yıldırım ÇV, Kıvak T, Sarıkaya M, Șirin Ș (2020) Evaluation of tool wear, surface roughness/topography and chip morphology when machining of Ni-based alloy 625 under MQL, cryogenic cooling and CryoMQL. J Mater Res Technol

59. Biksa A, Yamamoto K, Dosbaeva $\mathrm{G}$ et al (2010) Wear behavior of adaptive nano-multilayered AlTiN/MexN PVD coatings during machining of aerospace alloys. Tribol Int 43:1491-1499. https:// doi.org/10.1016/j.triboint.2010.02.008

60. Fox-Rabinovich GS, Beake BD, Yamamoto K et al (2010) Structure, properties and wear performance of nano-multilayered TiAlCrSiYN/TiAlCrN coatings during machining of Ni-based aerospace superalloys. Surf Coat Technol 204:3698-3706. https://doi.org/10.1016/j.surfcoat.2010.04.050

61. Fox-Rabinovich GS, Yamamoto K, Aguirre MH et al (2010) Multi-functional nano-multilayered AlTiN/Cu PVD coating for machining of Inconel 718 superalloy. Surf Coat Technol 204: 2465-2471. https://doi.org/10.1016/j.surfcoat.2010.01.024

62. Koseki S, Inoue K, Usuki H (2016) Damage of physical vapor deposition coatings of cutting tools during alloy 718 turning. Precis Eng 44:41-54. https://doi.org/10.1016/j.precisioneng. 2015.09.012

63. Koseki S, Inoue K, Morito S et al (2015) Comparison of TiNcoated tools using CVD and PVD processes during continuous cutting of Ni-based superalloys. Surf Coat Technol 283:353363. https://doi.org/10.1016/j.surfcoat.2015.10.071

64. Arunachalam RM, Mannan MA, Spowage AC (2004) Surface integrity when machining age hardened Inconel 718 with coated carbide cutting tools. Int J Mach Tools Manuf 44:1481-1491. https://doi.org/10.1016/j.ijmachtools.2004.05.005

65. Cantero JL, Díaz-Álvarez J, Miguélez MH, Marín NC (2013) Analysis of tool wear patterns in finishing turning of Inconel 718. Wear 297:885-894. https://doi.org/10.1016/j.wear.2012.11.004

66. Özel T, Ulutan D (2014) Effects of machining parameters and tool geometry on serrated chip formation, specific forces and energies in orthogonal cutting of nickel-based super alloy Inconel 100. Proc Inst Mech Eng B J Eng Manuf 228:673-686. https://doi.org/10. 1177/0954405413510291

67. Tsai YC, Hsieh JM (2004) An analysis of cutting-edge curves and machining performance in the Inconel 718 machining process. Int J Adv Manuf Technol 25:248-261. https://doi.org/10.1007/ s00170-003-1869-6

68. Devillez A, Le Coz G, Dominiak S, Dudzinski D (2011) Dry machining of Inconel 718, workpiece surface integrity. J Mater Process Technol 211:1590-1598. https://doi.org/10.1016/j. jmatprotec.2011.04.011
69. Zhang S, Li JF, Wang YW (2012) Tool life and cutting forces in end milling Inconel 718 under dry and minimum quantity cooling lubrication cutting conditions. J Clean Prod 32:81-87. https://doi. org/10.1016/j.jclepro.2012.03.014

70. Kaynak Y (2014) Evaluation of machining performance in cryogenic machining of Inconel 718 and comparison with dry and MQL machining. Int J Adv Manuf Technol 72:919-933. https:// doi.org/10.1007/s00170-014-5683-0

71. Wang F, Liu J, Shu Q (2017) Milling wear of carbide tool for processing nickel-based alloy in cryogenic based on the entropy change. Int J Adv Manuf Technol 90:1703-1713. https://doi.org/ 10.1007/s00170-016-9505-4

72. Venkatesana K, Mathewb AT, Devendiranc S et al (2018) Machinability study and multi-response optimization of cutting force, surface roughness and tool wear on $\mathrm{CNC}$ turned Inconel 617 superalloy using $\mathrm{Al}_{2} \mathrm{O}_{3}$ nanofluids in coconut oil

73. Ezugwu EO, Bonney J (2004) Effect of high-pressure coolant supply when machining nickel-base, Inconel 718, alloy with coated carbide tools. J Mater Process Technol 153-154:1045-1050. https://doi.org/10.1016/j.jmatprotec.2004.04.329

74. Hoier P, Klement U, Tamil Alagan N et al (2017) Characterization of tool wear when machining alloy 718 with high-pressure cooling using conventional and surface-modified $\mathrm{WC}-\mathrm{Co}$ tools. J Superhard Mater 39:178-185. https://doi.org/10.3103/ S1063457617030054

75. Attia H, Tavakoli S, Vargas R, Thomson V (2010) Laser-assisted high-speed finish turning of superalloy Inconel 718 under dry conditions. CIRP Ann Manuf Technol 59:83-88. https://doi.org/ 10.1016/j.cirp.2010.03.093

76. Kong X, Yang L, Zhang H et al (2015) Cutting performance and coated tool wear mechanisms in laser-assisted milling K24 nickelbased superalloy. Int J Adv Manuf Technol 77:2151-2163. https://doi.org/10.1007/s00170-014-6606-9

77. Singh A, Ghosh S, Aravindan S (2020) Flank wear and rake wear studies for arc enhanced HiPIMS coated AlTiN tools during high speed machining of nickel-based superalloy. Surf Coat Technol 381:125190

78. Richards N, Aspinwall D (1989) Use of ceramic tools for machining nickel based alloys. Int J Mach Tools Manuf 29:575-588. https://doi.org/10.1016/0890-6955(89)90072-2

79. Kitagawa T, Kubo A, Maekawa K (1997) Temperature and wear of cutting tools in high-speed machining of Inconel 718 and Ti6A16V2Sn. Wear 202:142-148. https://doi.org/10.1016/ S0043-1648(96)07255-9

80. Wayne SF, Buljan S-T (1990) Wear of ceramic cutting tools in Nibased superalloy machining. Tribol Trans 33:618-626. https://doi. org/10.1080/10402009008981997

81. Zhuang K, Zhu D, Zhang X, Ding H (2014) Notch wear prediction model in turning of Inconel 718 with ceramic tools considering the influence of work hardened layer. Wear 313:63-74. https://doi. org/10.1016/j.wear.2014.02.007

82. El-Bestawi MA, El-Wardany TI, Yan D, Tan M (1993) Performance of whisker-reinforced ceramic tools in milling nickel-based superalloy. CIRP Ann Manuf Technol 42:99-102. https://doi.org/10.1016/S0007-8506(07)62401-9

83. Narutaki N, Yamane Y, Hayashi K et al (1993) High-speed machining of Inconel 718 with ceramic tools. CIRP Ann Manuf Technol 42:103-106. https://doi.org/10.1016/S0007-8506(07) 62402-0

84. Lima FF, Sales WF, Costa ES et al (2017) Wear of ceramic tools when machining Inconel 751 using argon and oxygen as lubricooling atmospheres. Ceram Int 43:677-685. https://doi.org/10. 1016/j.ceramint.2016.09.214

85. Chen Y, Milner JL, Bunget $C$ et al (2013) Investigations on performance of various ceramic tooling while milling nickel-based superalloy. In: ASME 2013 International Manufacturing Science 
and Engineering Conference collocated with the 41st North American Manufacturing Research Conference. p V001T01A035

86. Peng R, Tong J, Tang X et al (2020) Crack propagation and wear estimation of ceramic tool in cutting Inconel 718 based on discrete element method. Tribol Int 142:105998

87. Sun J, Huang S, Ding H, Chen W (2020) Cutting performance and wear mechanism of SiAlON ceramic tools in high speed face milling GH4099. Ceram Int 46:1621-1630

88. Jianxin D, Lili L, Jianhua L et al (2005) Failure mechanisms of $\mathrm{TiB}_{2}$ particle and $\mathrm{SiC}$ whisker reinforced $\mathrm{Al}_{2} \mathrm{O}_{3}$ ceramic cutting tools when machining nickel-based alloys. Int J Mach Tools Manuf 45:1393-1401. https://doi.org/10.1016/j.ijmachtools. 2005.01.033

89. Gatto a, Iuliano L (1997) Advanced coated ceramic tools for machining superalloys. Int J Mach Tools Manuf 37:591-605. https:// doi.org/10.1016/S0890-6955(96)00075-2

90. Ezugwu EO, Bonney J, Fadare DA, Sales WF (2005) Machining of nickel-base, Inconel 718, alloy with ceramic tools under finishing conditions with various coolant supply pressures. J Mater Process Technol 162-163:609-614. https://doi.org/10. 1016/j.jmatprotec.2005.02.144

91. Sivalingam V, Zan Z, Sun J et al (2020) Wear behaviour of whisker-reinforced ceramic tools in the turning of Inconel 718 assisted by an atomized spray of solid lubricants. Tribol Int 106235

92. Focke AE, Westermann FE, Kemphaus J et al (1978) Wear of superhard materials when cutting super-alloys. Wear 46:65-79. https://doi.org/10.1016/0043-1648(78)90111-4

93. Ji W, Liu X, Fan M et al (2015) PCBN Tool wear characteristic in cutting superalloy GH706. Tribology 35:37-44. (in Chinese). https://doi.org/10.16078/j.tribology.2015.01.006

94. Costes JP, Guillet Y, Poulachon G, Dessoly M (2007) Tool-life and wear mechanisms of CBN tools in machining of Inconel 718. Int J Mach Tools Manuf 47:1081-1087. https://doi.org/10.1016/j. ijmachtools.2006.09.031

95. Bushlya V, Zhou J, Avdovic P, Ståhl JE (2013) Performance and wear mechanisms of whisker-reinforced alumina, coated and uncoated PCBN tools when high-speed turning aged Inconel 718. Int J Adv Manuf Technol 66:2013-2021. https://doi.org/10.1007/ s00170-012-4477-5

96. Li L, Wu M, Liu X et al (2018) Experimental study of the wear behavior of PCBN inserts during cutting of GH4169 superalloys under high-pressure cooling. Int J Adv Manuf Technol 95:19411951. https://doi.org/10.1007/s00170-017-1333-7

97. Ji W, Liu XL, Li YF et al (2012) The mechanisms of PCBN tools in turning GH4169. Adv Mater Res 500:73-81. https://doi.org/10. 4028/www.scientific.net/AMR.500.73

98. Pawade RS, Joshi SS (2011) Mechanism of chip formation in high-speed turning of Inconel 718. Mach Sci Technol 15:132152. https://doi.org/10.1080/10910344.2011.557974

99. Wu M, Zhao X, Ji W et al (2016) Generation mechanism of sawtooth chip in turning of GH4169 with PCBN tool. Aust J Mech Eng 52:179-186. (in Chinese). https://doi.org/10.3901/JME.2016. 03.179

100. Bushlya V, Zhou J, Ståhl JE (2012) Effect of cutting conditions on machinability of superalloy Inconel 718 during high speed turning with coated and uncoated PCBN tools. Procedia CIRP 3:370-375. https://doi.org/10.1016/j.procir.2012.07.064

101. Turkevich V, Bushlya V, Zhou JM et al (2012) Experimentation and modeling of chemical interaction of PCBN and Inconel 718. In: Proceedings of the 5th Swedish Production Symposium. pp 1-8

102. Khan SA, Soo SL, Aspinwall DK et al (2012) Tool wear/life evaluation when finish turning Inconel 718 using PCBN tooling. Procedia CIRP 1:283-288. https://doi.org/10.1016/j.procir.2012. 04.051
103. Ji W, Liu XL, Yan FG et al (2013) Investigations of surface roughness with cutting speed and cooling in the wear process during turning GH4133 with PCBN tool. Key Eng Mater 589 590:258-263. https://doi.org/10.4028/www.scientific.net/KEM. $589-590.258$

104. Cantero J, Díaz-Álvarez J, Infante-García D et al (2018) High speed finish turning of Inconel 718 using PCBN tools under dry conditions. Metals (Basel) 8:192. https://doi.org/10.3390/ met8030192

105. Tazehkandi AH, Shabgard M, Kiani G, Pilehvarian F (2016) Investigation of the influences of polycrystalline cubic boron nitride $(\mathrm{PCBN})$ tool on the reduction of cutting fluid consumption and increase of machining parameters range in turning Inconel 783 using spray mode of cutting fluid with compressed air. J Clean Prod 135:1637-1649. https://doi.org/10.1016/j.jclepro. 2015.12.102

106. Aramesh M, Montazeri S, Veldhuis SC (2018) A novel treatment for cutting tools for reducing the chipping and improving tool life during machining of Inconel 718. Wear 414-415:79-88. https:// doi.org/10.1016/J.WEAR.2018.08.002

107. Lei S, Devarajan S, Chang Z (2009) A study of micropool lubricated cutting tool in machining of mild steel. J Mater Process Technol 209:1612-1620. https://doi.org/10.1016/j.jmatprotec. 2008.04.024

108. Enomoto T, Sugihara T (2010) Improving anti-adhesive properties of cutting tool surfaces by nano-/micro-textures. CIRP Ann Manuf Technol 59:597-600. https://doi.org/10.1016/j.cirp.2010.03.130

109. Liu XL, Shi JK, Ji W, Wang LH (2018) Experimental evaluation on grinding texture on flank face in chamfer milling of stainless steel. Chin J Mech Eng 31:71. https://doi.org/10.1186/s10033018-0271-0

110. Yin S, Ji W, He G et al (2018) Experimental evaluation on texture of flank face on tool wear in chamfer milling of stainless steel. Int J Adv Manuf Technol 99:2929-2937. https://doi.org/10.1007/ s00170-018-2657-7

111. Tamil Alagan N, Zeman P, Hoier P et al (2019) Investigation of micro-textured cutting tools used for face turning of alloy 718 with high-pressure cooling. J Manuf Process 37:606-616. https://doi. org/10.1016/J.JMAPRO.2018.12.023

112. Corne R, Nath C, Mansori M El, Kurfess T (2016) Enhancing spindle power data application with neural network for real-time tool wear/breakage prediction during Inconel drilling. Procedia Manuf 5:1-14. https://doi.org/10.1016/j.promfg.2016.08.004

113. Wu D, Jennings $\mathrm{C}$, Terpenny J et al (2017) A comparative study on machine learning algorithms for smart manufacturing: tool wear prediction using random forests. J Manuf Sci Eng 139: 71018-71019. https://doi.org/10.1115/1.4036350

114. Ji W, Shi J, Liu X et al (2017) A novel approach of tool wear evaluation. J Manuf Sci Eng 139:1-8. https://doi.org/10.1115/1. 4037231

115. Ji W, Wang L (2017) Big data analytics based optimisation for enriched process planning : a methodology. Procedia CIRP 63: 161-166. https://doi.org/10.1016/j.procir.2017.03.090

116. Ji W, Yin S, Wang L (2019) A big data analytics based machining optimisation approach. J Intell Manuf. https://doi.org/10.1007/ s10845-018-1440-9

117. Wang L, Ji W (2018) Cloud enabled CPS and big data in manufacturing. In: Proceedings of 3rd International Conference on the Industry 4.0 Model for Advanced Manufacturing. Springer International Publishing, pp 265-292

Publisher's note Springer Nature remains neutral with regard to jurisdictional claims in published maps and institutional affiliations. 